\title{
Therapie des Trockenen Auges
}

\author{
Jonas Philipp Korbmacher (D) - Gerd Geerling
}

Eingegangen: 22. März 2021 / Angenommen: 28. Juni 2021 / Online publiziert: 13. September 2021

(C) Der/die Autor(en) 2021

Zusammenfassung Die Therapie des Trockenen Auges stellt eine schwierige Aufgabe für den behandelnden Augenarzt dar. Fortschritte in unserem Verständnis der Risikofaktoren, der Ätiologie und Pathophysiologie des Trockenen Auges haben zu einer Weiterentwicklung der Behandlungsstrategien geführt. Vor Beginn der Therapie ist die korrekte Zuordnung in eine wässrig-muzinöse Tränenfilmdysfunktion (Mindersekretion), in eine lipidbedingte Tränenfilmdysfunktion (hyperevaporative Form durch eine abnormen Meibom-Drüsen-Physiologie) oder in eine variable Kombination wichtig. Unter Berücksichtigung aktueller Empfehlungen der DOG, des BVA und des TFOS DEWS II Unterausschusses wurde ein Behandlungsalgorithmus abgeleitet, der ein schrittweises Vorgehen je nach Schweregrad der Erkrankung darstellt.

Schlüsselwörter Tränenfilmdysfunktion · Keratokonjunktivitis sicca · Empfehlung · Behandlungsstrategie · TFOS DEWS II

\section{Dry eye therapy}

Summary Dry eye therapy is a challenging task for the ophthalmologist. Advances in our understanding of the risk factors, etiology and pathophysiology of dry eye have led to further development of treatment strategies. Prior to initiation of therapy, the correct classification into aqueous-mucinous tear film dysfunction (hyposecretion), lipid-related tear film dysfunction (hyperevaporative form due to ab-

J. P. Korbmacher $(\bowtie) \cdot$ G. Geerling

Augenklinik, Universitätsklinik Düsseldorf,

Moorenstraße 5, 40225 Düsseldorf, Deutschland

Jonas.Korbmacher@med.uni-duesseldorf.de

G. Geerling

Geerling@med.uni-duesseldorf.de normal meibomian gland physiology), or a variable combination of both is essential. Taking into account current recommendations of the DOG, BVA and TFOS DEWS II subcommittee, a treatment algorithm was developed that represents a stepwise approach depending on the severity of the disease.

Keywords Tear-film-dysfunction •

Keratoconjunctivitis sicca - Recommendation .

Treatment · TFOS DEWS II

Die Therapie des Trockenen Auges - der Tränenfilmdysfunktion - gehört sicher zu den schwierigsten Aufgaben des Augenarztes, weil nicht auf den ersten Blick eine optimale Behandlungsstrategie zur Verfügung steht. Die oftmals hohe Erwartungshaltung der Patienten, die Beschwerden mit „einem einzigen Idealtropfen“ zu beseitigen, stellen die Arzt-PatientenBeziehung schnell auf die Probe.

Fortschritte in unserem Verständnis der Risikofaktoren, der Ätiologie und Pathophysiologie des Trockenen Auges haben zu einer Weiterentwicklung der Behandlungsstrategien geführt. In den letzten Jahren erlangte insbesondere die Meibom-Drüsen-Dysfunktion (MDD) mehr Bedeutung für die Einordnung von Symptomen und als diagnostisches Kriterium. Es wird allgemein angenommen, dass die meisten Menschen mit Symptomen des Trockenen Auges an einer variablen Kombination der wässrig-muzinösen Tränenfilmdysfunktion (Mindersekretion) oder der lipidbedingten Tränenfilmdysfunktion (hyperevaporative Form durch eine abnorme Meibom-DrüsenPhysiologie) leiden. Die ist daher auch therapeutisch zu berücksichtigen.

Neben der korrekten Diagnostik ist aber auch das ärztliche Gespräch über die Natur der Erkrankung und notwendige oder mögliche Therapieschritte ein 
wichtiger Teil der Entwicklung eines Behandlungskonzeptes. Patienten benötigen Geduld, Augenärzte die Fähigkeit der Zuwendung. Es sollte vor Beginn der Therapie klar sein, dass eine Behandlung schrittweise entwickelt werden muss und dass die Wirksamkeit manchmal erst nach Wochen oder Monaten eintritt und entsprechend Kontrollen erforderlich sind. Lokale, ursächlich wirkende Medikamente stehen mittlerweile zur Verfügung oder sind in der klinischen Erprobung und ergänzen zunehmend die symptomatische Therapie der Tränenfilmdysfunktion.

In einem Konsensusprozess der Tear Film and Ocular Surface Society (TFOS), dem Dry Eye Workshop-2 Report wurde auch ein Therapieschema entwickelt, das im Wesentlichen Grundlage der folgenden Empfehlungen ist [1].

\section{Beseitigung von Grundleiden}

Für die Therapie des Trockenen Auges stehen diverse therapeutische Maßnahmen zur Verfügung. Sind Grundleiden oder externe Faktoren allerdings offensichtlich, so müssen diese behandelt, beziehungsweise beseitigt werden.

\section{Lidfehlstellungen}

Bei Lidschlussinsuffizienz, Stellungsanomalien (z. B. mit Trichiasis), Kolobomen, Exophthalmus, oder Tumoren ist primär an eine operative Therapie $\mathrm{zu}$ denken.

\section{Beseitigung von Störfaktoren}

Externe Störfaktoren, wie z.B. Umweltverschmutzung, Rauchen, exzessive Bildschirmnutzung (inkl. Mobiltelefon), trockene Luft in überheizten oder klimatisierten Räumen können ein Trockenes Auge verursachen oder verschlechtern. Andererseits kann eine ungenügend korrigierte Refraktionsanomalie ein Trockenes Auge vortäuschen. Solche Faktoren sollten - soweit möglich - beseitigt werden.

\section{Kosmetika}

Alle Stoffe, seien es Salben oder Kosmetika, die im Lid oder Lidkantenbereich appliziert werden, können über die Lidkante in den Tränenfilm und so auf die Augenoberfläche gelangen und Symptome der Irritation auslösen. Bei Trockenem Auge oder chronischer Blepharitis sollten in der Lid- und Lidkantenregion keine Öle oder gar Duftstoffe enthaltende Produkte angewendet werden. Wimperntusche und Umweltschmutz sollten möglichst morgens und abends mit fettfreien, wasserlöslichen und hypoallergenen Spezialreinigern entfernt werden. Insbesondere Kontaktlinsenträgerinnen, die über einen reduzierten Tragekomfort klagen, sollten dies beachten. Eine qualitativ und quantitativ abgestimmte Auswahl lidrandnaher Kosmetik ist des- halb beim Trockenen Auge eine hilfreiche Ergänzung zur Basistherapie. Beratung auch auf diesem Sektor unterstreicht die Kompetenz des behandelnden Augenarztes.

\section{Patientenanleitung}

Die Information und Anleitung der Patienten im Umgang mit der Krankheit, ist vielleicht der wesentlichste Aspekt bei der Behandlung des Trockenen Auges. Die Patienten benötigen Unterstützung und Ermutigung. Sie sollten angehalten werden, ihren Augenarzt bei neuen Symptomen, wie z. B. Bindehauthyperämie, vermehrter Sekretbildung oder Schmerzen aufzusuchen, weil sie anfälliger für Infektionen der Augenoberfläche sind. Zusätzliche, schriftliche Informationen (Patientenbroschüren) können hier nützlich sein.

Den Patienten sollte erläutert werden, dass ihre Erkrankung zwar chronisch und eine langfristige Behandlung, im Allgemeinen mit Augentropfen, erforderlich ist, dass es aber auch ein großes Spektrum an Behandlungsoptionen gibt. Das komplexe Krankheitsbild sollte nicht bagatellisiert werden, denn dadurch fühlen sich Patienten nicht ernst genommen. Der Augenarzt sollte auf die Notwendigkeit der regelmäßigen Behandlung und Befundkontrolle hinweisen. Konkrete Hinweise und die exakte Festlegung der Tropffrequenz erscheinen ebenfalls geboten.

\section{Topische Ophthalmika}

Beim Trockenen Auge handelt es sich um ein ätiologisch und pathogenetisch sehr komplexes Krankheitsbild. Schon bei der Diagnostik gibt es kein einfaches und sicheres Testverfahren, sie erfordert Können und große klinische Erfahrung. Demgemäß schwierig gestaltet sich die Therapie des Trockenen Auges.

Heute steht eine große Zahl von Substitutionspräparaten zur Verfügung, die im Wesentlichen eine qualitativ und quantitativ nicht ausreichende Tränenproduktion ausgleichen sollen. Erste kausal wirkende Mittel sind seit geraumer Zeit auf dem Markt oder befinden sich in klinischer Erprobung. Der symptomatische Einsatz von Substitutionspräparaten ist aber nach wie vor einer der häufigsten primären Therapieschritte. Die Behandlung sollte immer schrittweise und nach Schweregrad erfolgen. Eine exakte Diagnostik und Zuordnung in „Mindersekretion“, „Hyperevaporation" oder in eine kombinierte Störung vorab ist wichtig, um neben der Substitution gezielte Ergänzungsbehandlungen zu verordnen.

\section{Tränensubstitutionsmittel}

Der Begriff „Künstliche Tränen“ ist in den meisten Fällen eine unzutreffende Bezeichnung, da die Zusammensetzung und Schichtung des Tränenfilms durch Tränensubstitutionsmittel nicht imitiert werden kann. Die meisten Präparate wirken als Benetzungsmittel. 
Nur wenige sind an die Elektrolytzusammensetzung des Tränenfilms angepasst und enthalten z.B. Kalium und Bicarbonat in ausreichender Dosierung. Zusätzliche Wirkmechanismen von Tränenersatzmitteln könnten die Reduktion der Tränenfilmosmolarität, die Entfernung entzündlicher Faktoren von der Augenoberfläche, die Hydratation von Muzin oder auch die Osmoprotektion der Epithelzellen sein. Historisch wurden zum Ausgleich der mangelhaften Tränenproduktion isotone, kochsalzhaltige Lösungen verwendet. Sie waren wegen ihrer kurzen Verweildauer und unausgewogenen Zusammensetzung nur von begrenztem Wert.

Wesentlich günstiger sind Präparate mit verlängerter Verweildauer auf der Augenoberfläche wie z.B. Carboxymethylcellulose (CMC), Hydroxypropylmethylcellulose (HPMC), Hyaluronsäure (HA), Polyvinylalkohol (PVA), Povidon (Polyvinylpyrrolidon, PVP), Hydroxypropylguar (HP Guar), Hydroxypropylcellulose (HPC), Tamarindensamenpolysaccharid (TSP), Polyacrylsäure (Carbomer). Durch eine Erhöhung der Tränenfilmdicke und längere Retentionsrate schützen sie das Auge besser vor Austrocknung und reduzieren Symptome. Augentropfen mit hoher Viskosität und einer längeren Retentionsrate auf der Augenoberfläche, können aber auch zu transienten Sehstörungen und unerwünschten Ablagerungen auf den Augenlidern und Wimpern führen. Dies kann möglicherweise ein Grund für eine verminderte Toleranz und Compliance sein. Deswegen werden sehr hochvisköse Augentropfen normalerweise für die Nacht und Tropfen mit niedrigerer Viskosität für den Tag empfohlen.

Carboxymethylcellulose (CMC) ist ein Zellulosederivat und wird in Zellwänden von Pflanzen ausgebildet. Es ist ein sehr häufig verwendetes viskositätserhöhendes Mittel in künstlichen Tränen sowie in Pharmazeutika, Lebensmitteln und Kosmetika. Die CMC kann an Hornhautepithelzellen binden und zur epithelialen Zellheilung beitragen. CMC-basierte Produkte haben sich als erfolgreich bei der Behandlung des milden bis mittelschweren Trockenen Auges in einer Anzahl der Studien erwiesen [2, 3].

Hydroxypropylmethylcellulose (Hypromellose, HPMC) ist ein visköses Polysaccharid und Zellulosederivat. HPMC ist seit vielen Jahren ein häufiger Bestandteil von Tränenersatzmitteln. Es ist in einer Vielzahl von Konzentrationen erhältlich (von 0,2 bis $0,8 \%)$ und wird häufig in Kombination mit anderen Komponenten angeboten. Aufgrund der breiten Verfügbarkeit und langjährigen Nutzung haben mehrere Studien die Wirksamkeit in der Behandlung untersucht und HPMC als ein sicheres und wirksames Mittel für die Therapie des geringen bis mäßigen Trockenen Auges etabliert [4].

Hyaluronsäure (HA) kommt physiologisch im Körper in der extrazellulären Matrix des weichen Bindegewebes, im Knorpel, in der Synovialflüssigkeit der Gelenke, in den Herzklappen, in der Haut und am Auge in Glaskörper, Kammerwasser und Tränenflüssigkeit
[5, 6] vor. Hyaluronsäure bindet Wasser, wirkt antioxidativ und reduziert die toxischen Effekte von Konservierungsstoffen. Es hat mucoadhäsive Eigenschaften, und zeigt deshalb eine hohe Verweildauer auf der Augenoberfläche. Die Wirksamkeit von Na-HyaluronatLösungen bei der Behandlung des Trockenen Auges wurde in mehreren klinischen Studien belegt [7]. Hamano und Mitarbeiter haben gezeigt, dass eine mindestens 0,1\%ige Lösung erforderlich ist, um den Tränenfilm zu stabilisieren [8]. Na-Hyaluronat wird in unterschiedlichen Konzentrationen und Viskositäten auf dem Markt angeboten. Es verbessert die subjektiven Beschwerden beim Trockenen Auge, erhöht die Tränenfilmaufreißzeit und hat einen protektiven Effekt auf das Oberflächenepithel [9-11]. Eine signifikante Verbesserung der Barrierefunktion der Hornhaut wurde durch photometrische Analysen nachgewiesen [12].

Eine Kombination von CMC und HA konnte im Mausmodell eine signifikant geringere HornhautFluoreszein-Färbung und höhere Becherzelldichte im Vergleich zur CMC- oder HA-Monotherapie erzielen. In einer multizentrischen Studie mit 305 Probanden mit Trockenem Auge, konnte eine kommerziell erhältliche Kombination von CMC + HA die Symptome und Anzeichen des Trockenen Auges besser reduzieren als eine kommerzielle verfügbare topische Alternativformulierung auf der Grundlage von CMC allein [13].

Polyvinylalkohol (PVA) ist ein Polymer, das die Oberflächenspannung erniedrigt. PVA-Lösungen haben eine geringere Viskosität als Zellulosederivate in vergleichbaren Konzentrationen. Die Lösungen sind klar und am Auge nicht irritierend.

Povidon (Polyvinylpyrrolidon, PVP) erhöht die Viskosität geringfügig, besitzt oberflächenaktive Eigenschaften und wird in künstlichen Tränen häufig verwendet. Seine Lösungen zeigen gute protektive Wirkung beim Trockenen Auge [14].

Hydroxypropylguar (HP Guar, HPG) stellt ein chemisch modifiziertes Naturprodukt dar. Es ist in Lösung flüssig und bildet bei Kontakt mit der Augenoberfläche ein Gel. HP-Guar bindet wahrscheinlich überwiegend an hydrophobe, ausgetrocknete und/ oder geschädigte Epithelzellareale. Es ähnelt in seiner Molekularstruktur dem Muzin der Augenoberfläche und kann deshalb gut am Hornhautepithel verankert werden. Produkte auf HP-Guar-Basis führen nachweislich zu einer Symptomreduktion, erhöhen die Schleimschichtdicke und schützen die Augenoberfläche $[15,16]$.

Hydroxypropylcellulose (HPC) ist ein Sammelbegriff für Celluloseether bei denen ein Teil der Hydroxygruppen als Ether mit Hydroxypropyl-Gruppen verknüpft sind. Therapiekonzepte mit löslichen HPC-Inlays wurden erstmals von der Food and Drug Administration (FDA) vor über 30 Jahren zugelassen. Der methodische Behandlungsansatz geriet aufgrund von schlechter Wirksamkeit und geringem Tragekomfort 
in Vergessenheit. Eine neuere, stäbchenförmige Variante wird in den unteren Fornix eingebracht. Es ist konservierungsmittelfrei und löst sich nach dem Einbringen in den Bindehautsack langsam (in $12 \mathrm{~h}$ ) auf und erhöht die Viskosität des Tränenfilms. Eine Multicenterstudie zeigte eine signifikante Symptomreduktion, geringere Hornhaut-Fluoreszein- und Bindehautfärbung [17]. Als unerwünschte Effekte kommt es zu vorübergehenden Visusschwankungen, Irritation, Verklumpung und Verklebung der Wimpern. Der Fornix muss ausreichend tief sein, um das Präparat sicher einsetzten zu können.

Tamarindensamenpolysaccharid (TSP) ist in seiner chemischen Struktur dem transmembranösen Oberflächenmuzin (MUC-1) ähnlich und hat eine hohe Viskosität. Rolando und Mitarbeiter konnten die positive Wirkung einer 0,5\%igen und $1 \%$ igen TSP-Präparation auf subjektive Symptome und Tränenfilmaufreißzeit bei der Behandlung des Trockenen Auges nachweisen [18].

Polyacrylsäure (Carbomer) - Hydrogele erweitern die Therapiemöglichkeiten wesentlich. Ihre Eigenschaften nähern sich dem konjunktivalen Muzin an. Die Viskosität ist gut einstellbar, so dass tropfbare Gele mit verlängerter Kontaktzeit auf der Augenoberfläche und Depotwirkung verfügbar sind. Es entsteht ein Gleit- und Schutzfilm, der trotz erhöhter Viskosität keine oder nur geringe Sehstörungen hervorruft.

Sowohl Hyaluronsäure, HP Guar, TSP als auch Carbomere sind als Muzinersatz einsetzbar.

\section{Osmoprotektion}

Als Schutz vor den Folgen erhöhter Osmolarität im Tränenfilm (Osmoprotektion) wurden Tränenersatzmittel mit sogenannten „kompatiblen Soluten“ wie Betaine, Glycerin, Erythritol und Levocarnitin (Lcarnitin) entwickelt, die gegen eine potenzielle Schädigung der Zellen durch hyperosmolare Tränen schützen sollen. Als kompatible Solute werden Substanzen bezeichnet, deren Akkumulation bei Wassermangel den Zellstoffwechsel nicht stört, sondern die Zelle sogar vor Schaden bewahrt. Es gibt eine Reihe von Studien, die einen positiven Effekt der kompatiblen Solute vermuten lässt. Eine in vitro Studie zeigte, dass L-Carnitin und Erythritol kultivierte humane Hornhautepithelzellen durch Aktivitätsreduktion der mitogenaktivierten Proteinkinasen vor hyperosmolaren Bedingungen schützt [19]. Eine Studie an Mäusen mit Trockenem Auge legt nahe, dass Osmoprotektiva die Hornhautstippung reduzieren, die Anzahl an Zellapoptosen und Zytokinen reduzieren sowie die Anzahl an Becherzellen erhöhen können [20].

Wenige Studien haben bisher die Auswirkungen von hypo- oder hyperosmolaren Tropfen auf die Tränenosmolarität untersucht. Gilbard und Kollegen führten eine Reihe von Experimenten am Kaninchenmodell durch, um zu zeigen, dass die Verwendung eines hypoosmolaren Gleitmittels verschiedene Ver- änderungen der Augenoberfläche rückgängig machen kann. Zwei neuere Studien mit hypotonen, auf Hyaluronsäure basierenden Tränenersatzmitteln, zeigte eine Verbesserung sowohl der Symptome als auch der verschiedenen Befunde des Trockenen Auges [21, 22].

Trehalose ist ein Disaccharid und kommt natürlicherweise in verschiedenen Pflanzen, Pilzen und zahlreichen nicht-Säugetierarten vor. Es ist an der Anhydrobiose beteiligt, welches die Fähigkeit von Pflanzen und Tieren beschreibt, Phasen nahezu vollständiger Austrocknung zu überdauern und nach Wiederzufuhr von Wasser die ursprünglichen Lebensfunktionen wiederaufzunehmen.

In-vitro- und In-vivo-Studien haben gezeigt, dass Trehalose Hornhautzellen vor dem Austrocknen schützt sowie Hornhaut- und Bindehautzellen vor Apoptose schützten kann [23, 24]. Es gibt Hinweise, dass Trehalose die UV-induzierte oxidative Schädigung durch Beschleunigung der Hornhautepithelregeneration reduziert, zur Wiederherstellung des osmotischen Gleichgewichts auf der Augenoberfläche beiträgt und vor Denaturierung von Zellmembranbestandteilen und damit die Homöostase der Hornhautzellen schützt. Augentropfenformulierungen, die sowohl HA als auch Trehalose enthalten, kombinieren die Schmiermitteleigenschaften von HA und zytoprotektiven Eigenschaften der Trehalose.

\section{Lipidsubstitution}

Lipidhaltige Tränenersatzmittel sind Emulsionen, in denen nicht lösliche Bestandteile in einer anderen Flüssigkeit fein dispergiert werden (Öl in Wasser). Emulsionen lassen sich durch die Tröpfchengröße grob in drei Kategorien gliedern: Makroemulsionen enthalten Tröpfchen, die größer sind als $100 \mathrm{~nm}$, Nanoemulsionen mit Tröpfchen zwischen 10 und $100 \mathrm{~nm}$ und Mikroemulsionen mit Tröpfchen $<10$ nm. Makroemulsionen sind trübe, weil die großen Tröpfchen Licht streuen. Sie können bei topischer Anwendung eine passagere Visusunschärfe verursachen. Eine kleinere Tröpfchengröße führt $\mathrm{zu}$ einer geringeren Lichtstreuung und minimiert die Unschärfe nach Instillation. Verwendet werden Phospholipide, gesättigte und ungesättigte Fettsäuren und Triglyzeride. Auch der Einsatz von Mineralöl, Rizinusöl, Olivenöl, GlycerinCarbomeren, Kokosnussöl, Sojabohnenöl, Lecithin, in Kombination mit emulgierenden Wirkstoffe und Tensiden, wurde beschrieben.

Präparate mit Triglyzeriden unterstützen die äußere, unpolare Schicht des Tränenfilms und tragen somit theoretisch zum Verdunstungsschutz bei. Polare Lipide wie Phospholipide hingegen führen $\mathrm{zu}$ einer Stabilisierung des Tränenfilms. Durch ihren hydrophilen und hydrophoben Anteil haben Phospholipide Grenzflächeneigenschaften und ermöglichen die Spreitung der Neutralöle auf der wässrigen Schicht des Tränenfilms. Phospholipide aus hochgereinigtem Sojalecithin stehen in Form eines Liposomensprays zur 
Therapie des Trockenen Auges zur Verfügung. Mehrere Studien haben gezeigt, dass lipidbasierte Tropfen und liposomale Sprays - auch nach Applikation auf die geschlossenen Augenlider, von wo sie durch die Lidmotilität in den Tränenfilm migrieren - die Befunde und Symptome des Trockenen Auges verbessern. Lipidhaltige Tränenersatzmittel bieten wahrscheinlich einen Vorteil bei evaporativen Störungen wie der MDD [25, 26].

Kürzlich wurden neuartige Augentropfen aus Perfluorhexyloctan (F6H8) eingeführt. Aufgrund seiner geringen Oberflächenspannung verteilt sich das Perfluorhexyloctan schnell auf der Augenoberfläche und bildet eine lang anhaltende Schutzschicht, die die Verdunstung der wässrigen Phase des Tränenfilms verhindert und die Scherkräfte des Augenlids beim Blinzeln reduziert. Da es sich bei PerfluorhexyloctanAugentropfen um eine 1-Komponenten-Flüssigkeit handelt, die nicht wässrig ist, ist in der Formulierung kein Bakterienwachstum möglich und sie enthält daher auch keine Konservierungsmittel. In einer rezenten Studie von Frings et al. führte die Behandlung mit Perfluorhexyloctan zu einer signifikanten Verbesserung der Lipidschichtdicke nach 12-wöchiger regelmäßiger Anwendung [27]. Es wird postuliert, dass F6H8 Lipide lösen kann und bei regelmäßiger Applikation pathologisch obstruierte Meibom-Drüsen wieder eröffnen kann [28].

Tab. 1 Trockenes Auge. Medikamentöse (topische) Therapieempfehlung (modifiziert nach der Leitlinie Trockenes Auge BVA und DOG 2019)

Topische Ophthalmika (ggf. kombiniert)

I. Tränenersatzstoffe sind Mittel der ersten Wahl

Oberflächenaktive Stoffe (z. B. Polyvinylalkohol, Polyvinylpyrrolidon, Zellu-

losederivate, Hyaluronsäuren, Carbomere)

Muzinanaloga, Osmoprotektiva, Elektrolyt-Substitution

Lipidhaltige Tränenersatzstoffe

Semifluorierte Alkane

Zubereitung als Tropfen, Gele oder Salben

Bei häufiger und langfristiger Applikationsnotwendigkeit und Allergie bevorzugt Konservierungsstoff-frei

II. Immunmodulation lokal

Steroide

Ciclosporin A

Lifitegrast

Omega-3 Fettsäuren

III. Serum-Augentropfen

Wirken als Tränenersatz und anti-inflammatorisch

IV. Tränenstimulation

Lokal (z. B. Ciclosporin)

Oder systemisch (z. B. Pilocarpin-Analoga)

V. Mucolytika

z. B. Acetylcystein $5-10 \%$ bei filifomer Keratopathie

VI. Vitamin-A-Säure

Vitamin-A-Säure 0,01\%, Tropfen (Tretinoin - Herstellung über Apotheke) bei Keratinisierung von Augenoberflächenepithel

\section{Elektrolyte}

Der präkorneale Tränenfilm ist reich an Elektrolyten, einschließlich Natrium, Kalium, Chlor, Magnesium und Kalzium. Bei der Sekretion sind Tränen isoton, obwohl die Zusammensetzung im Vergleich zum Serum höhere Kaliumkonzentrationen aufweist. Die Konzentration von Elektrolyten im Tränenfilm nimmt typischerweise durch Verdunstung und/oder bei reduzierter wässriger Produktion zu. Bisherige Studien legen nahe, dass bestimmte Elektrolytzusammensetzungen im Tränenersatzmittel einen positiven Effekt haben. Nur wenige am Markt befindliche Präparate versuchen die Elektrolytzusammensetzung des Tränenfilms zu imitieren. Die Verwendung von hypotonem Tränenersatzmittel, um durch die Anwendung wieder Isotonie $\mathrm{zu}$ erreichen, konnte sich bisher im klinischen Alltag nicht bestätigen.

\section{Therapeutischer Einsatz von Tränenersatzmitteln}

Im Handel werden ausreichend Varianten von Tränenersatzmitteln angeboten, so dass für jeden Patienten ein geeignetes Präparat gefunden werden kann. Tab. 1 fasst schematisch die von der Arbeitsgruppe „Trockenes Auge“ der BVA gegebenen Empfehlungen für die topische Therapie zusammen. Tränenersatzmittel werden ab der ersten Stufe empfohlen und können je nach Schweregrad mit anderen Therapieformen kombiniert werden. Im Einzelfall benötigt jeder Patient eine individuelle Therapieanweisung, -kontrolle und -führung. Eine Kombination verschiedener visköser Tränenersatzmittel ist möglich und oftmals sinnvoll. Salben stören am Tage den Fettanteil des Tränenfilms und bilden eine Sauerstoffbarriere. Zur Nacht können sie gegebenenfalls verwendet werden.

Die Frage konserviert oder unkonserviert ist abhängig von Befund und Tropffrequenz. Eine unkonservierte Therapie ist bei längerer und häufigerer Anwendungsdauer zu bevorzugen. Muss auf konservierte Tränenersatzmittel zurückgegriffen werden, sind Konservierungsmittel mit reduzierter Epitheltoxizität, wie Polyquad, sinnvoll.

\section{Meibom-Drüsen-Dysfunktion}

Das evaporative Trockene Auge ist häufig, wobei meist eine Dysfunktion der Meibom-Drüsen mit reduzierter Tränenfilmstabilität ursächlich ist. Die Dysfunktion äußert sich durch eingedicktes Sekret (Meibum), überschießender Verhornung der Drüsenausführungsgänge und der sichtbaren Drüsenöffnungen auf der Lidkante. Störungen der Lipidphase spielen bei über $70 \%$ der Sicca-Patienten eine Rolle. Mittlerweile sind mehrere Tränenersatzmittel auf dem Markt, die Lipide enthalten und somit die Lipidphase des Tränenfilms unterstützen. Präparate enthalten z.B. Triglyceride oder Phospholipide. Patienten und Ärzte sind aber - neben der Substitutionstherapie - darauf ange- 
Abb. 1 LipiFlow ${ }^{\circledR}-S y s t e m$ (Firma TearScience ${ }^{\circledR}$, Morrisville, NC, USA). zur Erwärmung und Massage der Lider in einer 12-minütigen Behandlung. Bildschirminterface und steril verpackter Einmalapplikator. Eine technisch assistierte Lidkantenmassage (Druck und Wärme) bei Meibom-Drüsen-Dysfunktion
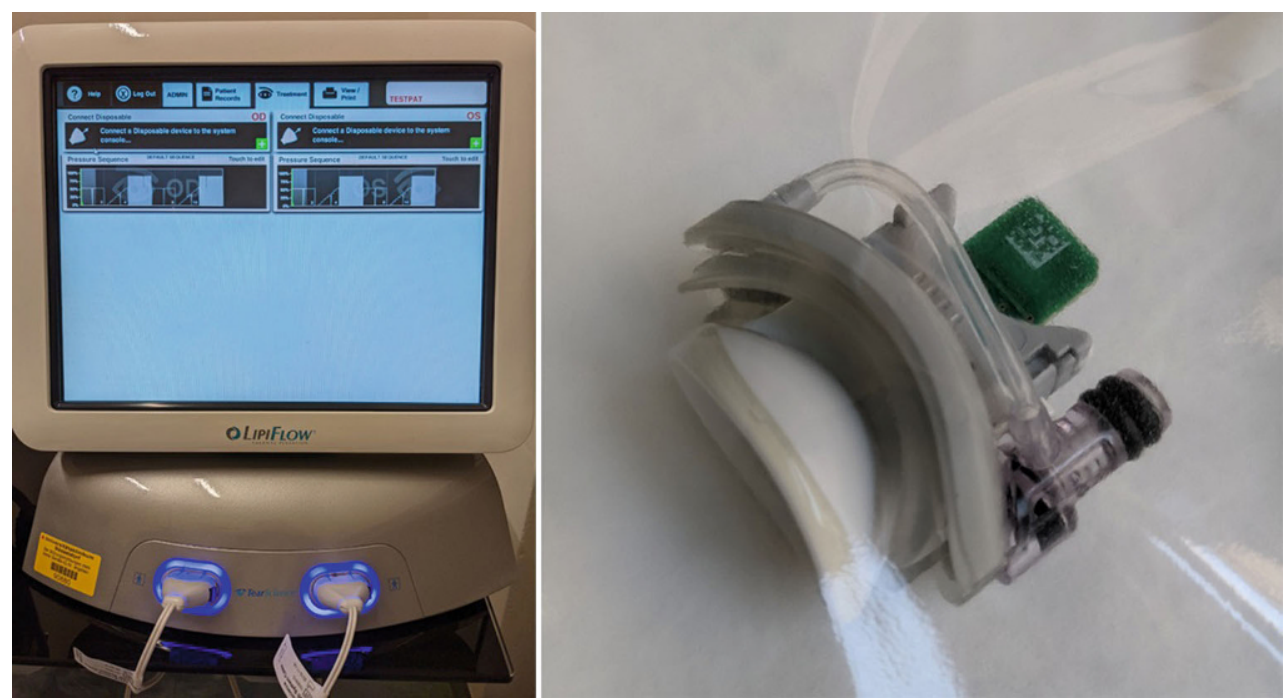
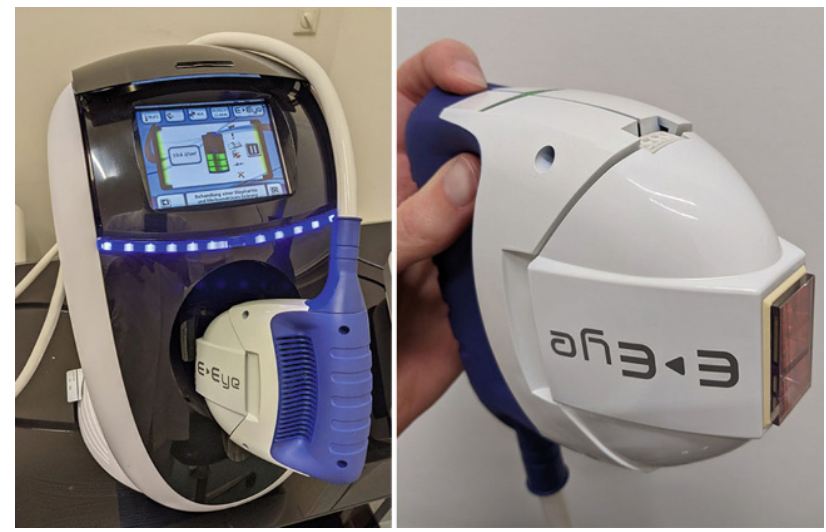

Abb. 2 E-Eye „Intense pulsed light“ (Firma E-Swin, Houdan, Frankreich) IPL-Gerät mit Handapplikator. Xenon Blitzlicht emittiert Licht im Wellenlängenbereich 500 bis $1200 \mathrm{~nm}$. Periokuläre Anwendung zur Stimulation bei Meibom-DrüsenDysfunktion

wiesen, die Talgproduktion der erkrankten MeibomDrüsen zu fördern und den Lipidfilm zur Ausbreitung an die Tränenoberfläche zu bringen. Das Sekret der Hauttalgdrüsen soll jedoch nicht in den Tränenfilm gelangen. Deshalb ist oftmals eine sog. Lidrandhygiene (Säuberung der Lidkante, Entfernung von verschupptem Hautmaterial, Entfernung von verkrustetem Sekret), Applikation von Wärme, z.B. in Form von Kompressen und Lidrandmassage zur Lidkante hin notwendig. Die Wärmeanwendung ist notwendig, um das Meibum zu verflüssigen, aus den MeibomDrüsen in die Tränen zu mobilisieren, um sich anschließend auf der Augenoberfläche zu verteilen. Die erforderliche Temperatur und die Dauer sind nicht endgültig geklärt. Verschiedenen Studien lassen vermuten, dass die Erwärmung der einzelnen MeibomDrüsen auf eine Temperatur von $>40^{\circ} \mathrm{C}$ wahrscheinlich für eine optimale Behandlung erforderlich ist [1]. Zur Lidkantenpflege sind speziell entwickelte Lösungen, Lidreinigungspads oder feuchte Wattestäbchen hilfreich.

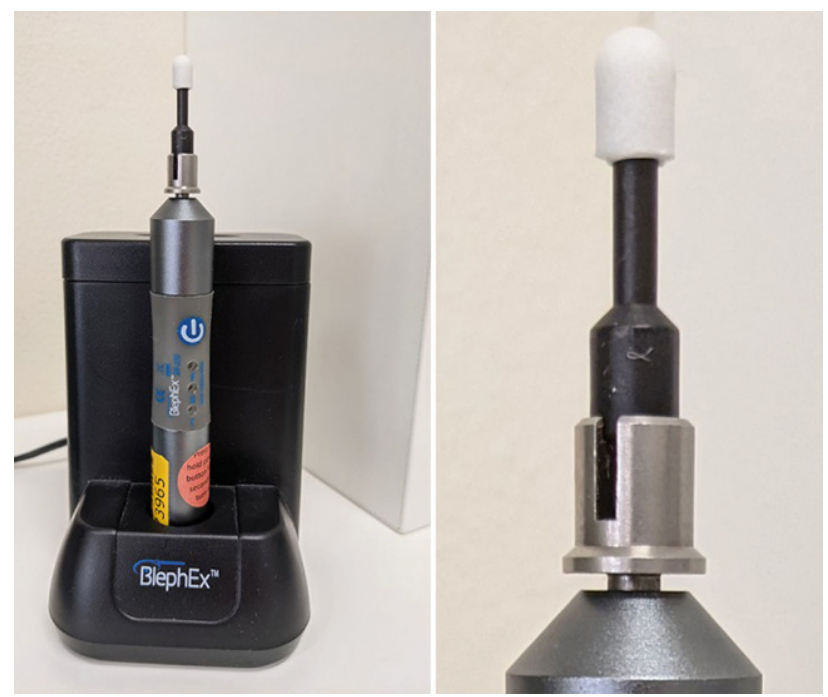

Abb. 3 Blephex ${ }^{\mathrm{TM}}$ (Firma BlephEx ${ }^{\circledR}$ LLC., Franklin, TN, USA) zur Entfernung von keratinisiertem Material. Eine mechanische Reinigung der Lidkanten mit rotierendem Bürstenkopf und Reinigungsschaum bei Meibom-Drüsen-Obstruktion

Trotz der nachgewiesenen Wirksamkeit von heißen Kompressen ist die Compliance aufgrund des Zeitbedarfs und des täglichen Aufwandes reduziert. Alternativ stehen Wärmebrillen mit unterschiedlichen aktiven und passiven Wärmequellen u. a. technische Hilfsmittel zur Verfügung. Das LipiFlow ${ }^{\circledR}$-System dient zur Erwärmung und Massage der Lider in einer 12-minütigen Behandlung (Abb. 1). Unkontrollierte und kontrollierte Studien legen eine Wirksamkeit und Sicherheit des Geräts mit Verbesserung von okulären Symptomen, Meibom-Drüsen-Funktion und Tränenfilmaufreißzeit nahe [29, 30].

Das „Intense pulsed light“ (IPL)-Verfahren, das Licht von 500-1200 nm Wellenlänge abgibt, ist weit verbreitet in der Dermatologie und Kosmetikindustrie und wird zur Behandlung von Teleangiektasien, Reduktion von Hämangiomen oder venösen Malformationen 
und pigmentierten Hautläsionen eingesetzt (Abb. 2). Eine Verbesserung der Meibom-Drüsen-Funktion, der Tränenfilmqualität sowie der okulären Symptome wurde nach IPL-Behandlung an der periokulären Region beschrieben [31].

Die intraduktale Meibom-Drüsen-Sondierung wurde erstmals 2010 beschrieben [32]. Neben der Erstbeschreibung konnte in einer darauffolgenden Studie im Vergleich zum unbehandelten Partnerauge die Tränenfilmaufreißzeit, Visus, Schmerz und Photophobie verbessert werden [33]. Im Hinblick auf die Invasivität des Verfahrens und die Möglichkeit der Schädigung des komplexen Duktalsystems sind weitere gut angelegte Studien notwendig. Standardisierte Sonden sind jedoch mittlerweile nicht mehr erhältlich.

Einer der primären Mechanismen der Obstruktion der Meibom-Drüsen ist die Hyperkeratinisierung des Lidrandes und der Drüsenöffnungen. Keratinisiertes Material kann sich innerhalb der Drüsenausführungsgänge sammeln und diese obstruieren, so dass das Meibum dann nicht mehr in den Tränenfilm gelangen kann. Vom sogenannten Debridement und Scaling der Lidkanten mittels Hockeymesser wurde erstmals 2013 berichtet [34]. Von der Industrie werden hierfür Systeme mit rotierenden Bürstenköpfen und Reinigungsschäumen vermarktet (Abb. 3). Es wird angenommen, dass diese Technik durch die mechanische Entfernung von Ablagerungen und Keratinisierung einen erhöhten Fluss von Meibum in den Tränenfilm ermöglicht. Größere kontrollierte Studien sind notwendig, um die bisher positiven Berichte zu bestätigen.

Bei eindeutig bakterieller Blepharitis sind lokale Antibiotika (z.B. Erythromycin, Gentamicin, Ofloxacin), bevorzugt als Salbentherapie, angezeigt. Bei ausgeprägter Entzündungsaktivität ist die kurzzeitige Anwendung steroidhaltiger Augensalben auf den Lidrand sinnvoll.

Die Wirksamkeit von topischem Azithromycin bei der Behandlung der Meibom-Drüsen-Dysfunktion wird auf seine entzündungshemmenden und antibakteriellen Eigenschaften zurückgeführt [35]. Darüber hinaus deuten neuere Erkenntnisse darauf hin, dass Azithromycin die zelluläre Akkumulation von Cholesterin, Cholesterinestern, Phospholipiden und Lysosomen erhöht [36]. Dieser lipid-stimulierende Effekt von Azithromycin auf das Meibom-DrüsenEpithel scheint es bei anderen antibiotischen Präparaten nicht zu geben [37]. Wir empfehlen als Therapieschema zunächst $2 \times$ tgl. - für 3 Tage, danach für 4 Wochen 1 tgl. als Tropfapplikation mit oder ohne Massage der Lidkanten. Die systemische Antibiotikatherapie bei durch Blepharitis hervorgerufener Benetzungsstörung dient in erster Linie der Modulation des Meibums. Tetrazykline verringern die Aktivität der Kollagenase, Phospholipase A2 und verschiedener Matrixmetalloproteinasen. Darüber hinaus reduzieren sie die Produktion von IL-1 und TNF $\alpha$. In hohen Konzentrationen unterdrücken sie die durch Staphylokokkenexotoxin induzierten Zytokine und Chemokine und verbessern die Fließfähigkeit des Meibums. Eine antiangiogene Wirkung ist bei der Behandlung der Rosazea zusätzlich von Vorteil. Bei Langzeitanwendung von Doxycyclin ist neben der Photosensitivität außerdem eine Hepatotoxizität möglich, sodass hier regelmäßige Kontrollen der Leberfunktion angezeigt sind. Bisher wurden keine randomisiert, kontrollierten Studien publiziert, die eine höhere Effektivität von Antibiotika im Vergleich zur Lidrandhygiene oder anderen Therapien nachweisen konnten. Die optimale Dosierung von Tetrazyklinen für die Behandlung des Trockenen Auges ist bisher nicht etabliert und es existiert eine Vielzahl von Dosierungsschemata (von $40 \mathrm{mg} / \mathrm{Tag}$ bis hin zu zweimal $200 \mathrm{mg} / \mathrm{Tag}$ [38, 39]). Doxycyclin zur Behandlung der Rosazea wurde in Form von Hartkapseln mit veränderter Wirkstofffreisetzung (slow release) in den USA 2006 und in Deutschland 2009 zugelassen (Oraycea $^{\circledR}$, in einigen Ländern auch Oracea ${ }^{\circledR}$ ). Eine langfristige DoxycyclinBehandlung in dieser Dosierung (40 mg) übt wahrscheinlich keinen antibiotischen Selektionsdruck aus, führt nicht zur Entwicklung von Antibiotikaresistenzen und stellt damit eine wirksame und sichere Therapie der okulären Rosazea dar. Die Therapie mit oralem Doxycyclin muss über Wochen bis Monate fortgesetzt werden.

\section{Stimulation der wässrig-muzinösen Phase des Tränenfilms}

Bei der klassischen Keratoconjunctivitis sicca werden Tränensubstitutionspräparate der verschiedensten Art sehr effektiv eingesetzt. Präparate wie Carbomere, Hyaluronsäure, HP Guar und Tamarindensamenextrakt bewähren sich bei zunehmender Epithelschädigung, da die Benetzung trotz gestörter apikaler Membranen mit fehlenden Muzinrezeptoren (Glykokalyx) gewährleistet bleibt. Sie ähneln in ihrer Struktur zum Teil dem Muzin der Augenoberfläche und können deshalb in Wechselwirkung mit dem Oberflächenepithel treten. Vom Patienten wird der schmerzlindernde Effekt als angenehm wahrgenommen.

Rebamipide-Augentropfen gehören in die Gruppe der Muzinsekretagoga und sind derzeit in Japan zugelassen. Diese stimulieren die Produktion $\mathrm{Mu}-$ zin-ähnlicher Glykoproteine in humanen Hornhautepithelzellen und erhöhen dadurch die Spiegel von MUC1, MUC4 und MUC16. In offenen Multicenterstudien konnte Rebamipide $2 \%$ die subjektiven Symptome und objektiven Zeichen des Trockenen Auges verbessern [40].

Der Wunsch nach Stimulation der Tränensekretion bei einer reduzierten Tränenproduktion (im SchirmerTest oder der Tränenfilmmeniskometrie) liegt nahe. Dieser Ansatz kann auf verschiedene Weise verfolgt werden. Eledoisin (Eloisin ${ }^{\circledR}$, Fa. Alcon-Cusi, Barcelona, Spanien), ursprünglich ein Polypeptid aus Speicheldrüsen mediterraner Tintenfische, wurde in Augentropfenform appliziert, wenn alle anderen Thera- 
piemöglichkeiten ausgeschöpft waren. Das Präparat ist jedoch mittlerweile auch über die internationale Apotheke nicht mehr verfügbar. Neue Wirkstoffe wie Lacritin, ein Glykoprotein mit prosekretorischer Aktivität in der Tränendrüse und mitogener Wirkung im Hornhautepithel, befinden sich in klinischen Studien. Auch unter kurzfristiger antientzündlicher Therapie kann ein Anstieg der Tränenproduktion im SchirmerTest beobachtet werden.

Eine Sekretionssteigerung der Tränendrüse ist auch durch orale Gabe cholinerger Substanzen wie Pilocarpin (Salagen ${ }^{\circledR}$ ) und Cevimeline (USA) möglich. Beide Präparate sind kommerziell verfügbar für die Behandlung des Sjögren-Syndroms. Die Therapie sollte mit geringer Dosis (Salagen $5 \mathrm{mg}$ Filmtabletten pro Tag) begonnen werden. In Abhängigkeit von der Arzneimittelwirksamkeit und -Verträglichkeit kann die Dosis dann schrittweise auf die Tagesdosis von dreimal $5 \mathrm{mg}$ pro Tag gesteigert werden. $\mathrm{Zu}$ den häufig berichteten unerwünschten Nebenwirkungen gehörten Kopfschmerzen, vermehrtes Schwitzen, Bauchschmerzen und Übelkeit. Die Wirksamkeit von oralen Sekretagogen scheint bei der Behandlung von Mundtrockenheit wirksamer als bei Augentrockenheit [41].

Diquafosol-Tetranatrium 3\% (Diquas ${ }^{\circledR}$; Santen, Osaka, Japan) ein purinerger P2Y2-Rezeptor-Agonist, ist in Japan und Südkorea zugelassen. Es erhöht die Wasser- und Muzin-Sekretion aus konjunktivalen Epithelzellen und Becherzellen, was zu einer verbesserten Stabilität des Tränenfilms führt. Randomisiert kontrollierte Studien konnten nach Anwendung von topischem Diquafosol eine Besserung der okulären Symptome und Besserung der Oberflächenbefunde nachweisen [42]. In den USA konnte DiquafosolTetranatrium keine FDA-Zulassung erreichen.

\section{Konservierungsmittel in Augentropfen}

Augentropfen sind nach dem deutschen Arzneibuch sterile, wässrige oder ölige Lösungen oder Suspensionen eines oder mehrerer Wirkstoffe zur tropfenweisen Anwendung am Auge. Wässrige Zubereitungen in Mehrdosisbehältnissen müssen ein Konservierungsmittel in angemessener Konzentration enthalten, falls das Präparat nicht selbst schon entsprechende antimikrobielle Eigenschaften hat. Bei industriell hergestellten Augentropfen gibt es heute durch die Produktions- und Kontrollmaßnahmen eine hohe Sicherheit, damit die Tropfen das Werk steril verlassen und auch steril in die Hand der Patienten kommen.

\section{Sinn und Anforderungen an Konservierungsmittel}

Konservierung wird zum Schutz von Augentropfen vor Kontamination während der Gebrauchsdauer vorgeschrieben. Früher war es für Apotheker äußerst aufwendig, Augentropfen steril herzustellen, abzufüllen und ordnungsgemäß zu stabilisieren. In einem Gutachten von 1964 über unkonservierte Augentrop- fen, die mehrere Wochen lang von Patienten benutzt worden waren, heißt es zu dieser Problematik wörtlich, „dass sie von Spülwasser nicht mehr zu unterscheiden waren und eine pharmakologische Wirkung nicht mehr nachweisbar war." Schwere bakterielle Keratitiden bis hin zum Augenverlust durch infizierte Augentropfen sind beschrieben worden. Demgemäß wurde es als Fortschritt angesehen, dass der Gesetzgeber im Deutschen Arzneibuch 1978 eine angemessene Konservierung von Augentropfen in Mehrdosisbehältnissen vorschrieb.

Konservierungsmittel sollen u.a. folgende Forderungen erfüllen:

- Kompatibilität mit allen übrigen Bestandteilen der Lösung und des Behältnisses

- Langdauernde Wirksamkeit

- Breites antimikrobielles Spektrum

- Keine Toxizität oder Irritation der Augenoberfläche

Für jede Formulierung muss individuell das bestgeeignete Konservierungsmittel gesucht werden. Die Verträglichkeit von Konservierungsmitteln am Auge schränkt die Auswahl unter den bekannten Konservierungsmitteln auf quarternäre Ammoniumsalze, wie z.B. Benzalkoniumchlorid, Cetrimid, Cetalkoniumchlorid und Polyquad, Alkohole wie Chlorobutanol oder Phenylethanol sowie Quecksilberverbindungen, z. B. Thiomersal, und Parabene ein. Im Vergleich zu Benzalkoniumchlorid zeigen Polyquad, NatriumChlorite und Natrium-Perborate eine geringere Toxizität [43].

\section{Unerwünschte Wirkungen von Konservierungsmitteln}

Toxische Reaktionen auf Konservierungsmittel mit Ausbildung einer follikulären Konjunktivitis sind häufig und dosisabhängig. Circa $10 \%$ der okulären Reaktionen auf Konservierungsstoffe sind allergischer Natur. Hypersensitivitäten auf Thiomersal und Benzalkoniumchlorid treten bei 5-10\% der Bevölkerung auf. Okuläre Kontaktallergien sind gehäuft bei individueller Empfindlichkeit, langdauernder Medikamenteneinnahme und vorbestehender Liddermatitis.

Alkohole wie Chlorobutanol stören wegen ihrer Lipidlöslichkeit die Zellmembranlipide. Auch Phenole binden an die Zellmembran und erhöhen die Permeabilität. Kationische Substanzen wie Benzalkoniumchlorid oder Cetrimid stören die Barrierefunktion der Zellwand. Sie können im Gewebe gespeichert werden. Quecksilberorganische Verbindungen, wie Thiomersal, binden SH-Gruppen von Enzymen und stören so den intrazellulären Metabolismus. Man kann aus diesen Angriffspunkten ersehen, dass nur eine relative Selektivität möglich ist und die gewählte Konzentration einen Kompromiss darstellt.

Dosisabhängige zytotoxische Hornhaut- und Bindehautepithelveränderungen wurden elektronen- und fluoreszenzmikroskopisch bereits unterhalb der in Augentropfen üblichen Konzentration nachgewiesen 
[44]. Benzalkoniumchlorid alteriert jedoch auch direkt den Tränenfilm und fördert Entzündungsvorgänge an der Augenoberfläche [45, 46]. Nach Daueranwendung von konservierten Augentropfen findet sich z.B. oft eine Keratitis punctata superficialis oder eine Verkürzung der Tränenfilmaufreißzeit. Bei allen längerfristig angewendeten Ophthalmika, also nicht nur Tränensubstitutionspräparaten sondern z. B. auch Antiglaukomatosa ist dies zu beachten. Eine vernarbende Konjunktivitis bis hin zum Pseudopemphigoid bei chronischer Glaukomtherapie ist ein gutes Beispiel für die Gefahr der Induktion eines irreversiblen Augenoberflächenschadens durch Augentropfen.

Konservierungsmittelfreie Präparate sollten bei Patienten mit nachgewiesener Allergie auf Konservierungsmittel, manifesten Störungen des Tränenfilms oder Erkrankungen des Hornhaut- und Bindehautepithels oder häufiger, langfristiger Applikation von Augentropfen (mehr als $4 \times$ tgl.) gewählt werden. Sie sind weiterhin sinnvoll bei sonstigen allergischen Erkrankungen der Augenoberfläche oder chronisch-entzündlichen Grunderkrankungen wie z. B. dem vernarbenden Pemphigoid sowie während des Kontaktlinsentragens.

Prinzipiell gilt: Je schwerer das Trockene Auge und je länger und häufiger eine Tropfenapplikation erforderlich ist, desto eher sind konservierungsmittelfreie Präparate zu wählen.

\section{Serum-Augentropfen}

Neben dem reinen Wasseranteil fehlen bei einem Mangel der wässrigen Tränenfilmphase bestimmte Tränenproteine wie Laktoferrin, Lysozym, Laktoperoxidase, Transferrin, Lipocalin und Phospholipase A, epidermaler Wachstumsfaktor, Endothelin-1, Basic fibroblastic growth factor (bFGF), Transforming growth factor $\beta$ (TGF- $\beta$ ), Hepatocyte growth factor (HGF), Schilddrüsenhormone, Retinol u.a.

Autologes Serum, das eine Vielzahl der genannten Faktoren enthält, wird erfolgreich z.B. bei Graftversus-Host-Disease, Stevens-Johnson-Syndrom u.a. Formen der schweren Keratoconjunctivitis sicca, angewendet [47]. Es verbessert subjektive Symptome und objektive Zeichen des Trockenen Auges und führt in vitro zur Hochregulierung von MUC-1 aus konjunktivalen Epithelzellen. Autologes Serum wird patientenindividuell hergestellt, ist bis $\mathrm{zu} 6$ Monate bei $-20^{\circ}$ stabil zu lagern und wird in Konzentrationen von $20-100 \%$ verabreicht [48].

Zellkulturergebnisse deuten darauf hin, dass die Proliferation von Epithelzellen, durch geringer konzentriertes Serum (20\%), die Epithelmigration aber durch höhere Serumkonzentrationen (50-100\%) begünstigt wird [49, 50]. Zur Abheilung von Epitheldefekten sollte daher bevorzugt hochkonzentriertes Serum verwendet werden [51]. Um eine gute Therapieadhärenz zu sichern sind möglichst nutzerfreundliche Applikationsgefäße sinnvoll [52].
Allogenes Serum kann eine Alternative für bestimmte Patientengruppen (aktive systemische Entzündung, Säuglinge, multimorbide Ältere, Menschen mit chronischer Anämie oder effektiver Antikoagulation) darstellen. Hierbei bestehen weiterhin Bedenken hinsichtlich des theoretischen Risikos einer Immunantwort auf fremde Antigene und aufgrund des Infektionsrisikos.

Rechtliche Aspekte und hohe Therapiekosten erschweren weiterhin die breitflächige Anwendung von Serum-Augentropfen in der Therapie der Keratoconjunctivitis sicca.

\section{Antientzündliche Therapie}

\section{Kortikosteroide}

Marsh und Mitarbeiter berichteten 1999 über die Anwendung unkonservierter Kortikosteroid-Augentropfen in der Therapie der Keratoconjunctivitis sicca bei Sjögren-Syndrom [53]. Sie behandelten 21 Patienten mit Methylprednisolon 1\% 3-4×/d für zwei Wochen und konnten eine über den Therapiezeitraum hinausgehende, anhaltende subjektive Besserung der Symptome sowie eine Reduktion der Hornhautstippung und filiformen Keratopathie beobachten.

Gerade bei Siccapatienten mit entzündlich veränderter Augenoberfläche, bei Autoimmunerkrankungen oder im Rahmen einer Graft-versus-HostReaktion nach Knochenmarkstransplantation ist der Einsatz einer kurzzeitigen lokalen „Steroidkur“ über zwei bis vier Wochen angezeigt. Da das Trockene Auge definiert ist als eine Erkrankung bei der Entzündung eine wesentliche pathogenetische Rolle spielt, sind Kortikosteroide nicht nur für das schwere Trockene Auge im Rahmen von Autoimmunerkrankungen und GVHD sinnvoll, sondern werden bereits in Stufe 2 des DEWS-Schemas empfohlen, also auch ohne Autoimmunerkrankung. Da sich aufgrund der möglichen Nebenwirkungen eine lokale Steroid-Langzeittherapie verbietet, ist bei einem guten Ansprechen die Fortsetzung der antientzündlichen Therapie mit Ciclosporin A Augentropfen zu erwägen.

\section{Nicht-Steroidale-Immunmodulatoren}

Mit Ausnahme von Ciclosporin wurden vergleichsweise wenige klinische Studien mit immunmodulierenden Medikamenten bei Personen mit Trockenem Auge durchgeführt. Der Wirksamkeitsnachweis innerhalb dieser therapeutischen Gruppe bietet potenziell wichtige Hinweise auf die Pathogenese und könnte zu neuen Entwicklungen mit nachweislichem Nutzen für die Patienten führen.

\section{Ciclosporin A (CsA)}

Ciclosporin A (CsA) ist ein immunmodulierendes Medikament, das zunächst hauptsächlich in der Transplantationsmedizin, seit Längerem auch in der Oph- 
thalmologie sowie bei chronischen Autoimmunerkrankungen eingesetzt wird. Es wurde 1970 aus einem Pilz (Tolypocladium inflatum Gams) als Antimykotikum isoliert und stellt ein zyklisches Undekapeptid mit einem Molekulargewicht von 1203 D dar.

CsA wirkt selektiv immunsuppressiv, indem es die Reaktion zytotoxischer T-Zellen auf ein Antigen bereits in der Frühphase blockiert. Dabei wirkt es durch

- die Blockade der Interleukin-2 (IL-2)-Produktion und anderer Zytokine, z. B. Interferon $\gamma$,

- die Blockade der Proliferation und der klonalen Expansion von T-Lymphozyten,

- die Blockade der Aktivierung zytotoxischer T-Lymphozyten und

- die Blockade der Funktion von Monozyten und Makrophagen durch inhibierte Antigenpräsentation,

- die Blockade von T-Zell-abhängiger B-Zell-Immunität.

Ein weiterer Wirkmechanismus von CsA im Tierversuch besteht in der Ausschüttung sensorischer Neurotransmitter (z. B. Substance P) und der Stimulierung von parasympathischen Muskarinrezeptoren verbunden mit einem erhöhten Tränenfluss nach 3 Tagen [54, 55].

Um die Nebenwirkungen der oralen CsA-Therapie wie Nephrotoxizität, arterielle Hypertonie, Hepatotoxizität, Gingivahyperplasie und Hypertrichose zu umgehen, wurden Formen der lokalen CsA-Anwendung am Auge entwickelt. Typische Vehikel für das lipophile CsA waren in Apothekenzubereitungen von Augentropfen zunächst vor allem Pflanzenöle (Olivenöl, Maisöl, Rizinusöl). Aufgrund seiner Lipophilie ist die intraokulare Penetration von CsA bei intaktem Epithel schlecht. Es akkumuliert hauptsächlich in der Hornhaut und Konjunktiva.

Seit 2015 ist eine unkonservierte kationische Emulsion mit einer CsA-Konzentration von 0,1\%, die einmal täglich appliziert werden soll, in Europa zugelassen und für Erwachsene mit schwerer Keratitis auf GKV-Kosten verordnungsfähig. Zwei randomisierte, doppelmaskierte, kontrollierte klinische Studien (SANSIKA, SICCANOVE) belegten die Wirksamkeit und Sicherheit bei Keratoconjunctivitis sicca. Hier waren Schmerzen nach der Instillation die am häufigsten berichtete Nebenwirkung. In der Regel wird eine mindestens 6-monatige Therapie empfohlen. In Studien betrug die mediane Therapiedauer fast 2 Jahre (7 bis 51 Monate). Danach benötigten allerdings nur noch sehr wenige Patienten $(6,5 \%) \mathrm{zu}$ einem späteren Zeitpunkt (Median $=40$ Monate) erneut eine CsA-Therapie [56, 57].

\section{Kortikosteroide und CsA-Therapie}

In einer prospektiv, doppelmaskierten, multizentrischen klinischen Studie beschleunigte und verstärkte eine zweiwöchige, topische Therapie mit $0,5 \%$ Loteprednol vor Beginn der CsA-Langzeittherapie
$(0,05 \%)$ die Symptomlinderung, die Verbesserung des Schirmer-Tests sowie der Hornhaut-FluoreszeinFärbung gegenüber einer alleinigen topischen CsAoder Benetzungstherapie [58]. Zusätzlich konnte die Loteprednol-Induktionstherapie die Häufigkeit von Brennen und Stechen bei der Anwendung von CsA reduzieren. Ähnlich verhält es sich bei der Behandlung mit höher dosiertem $1 \%$ igem CsA. Somit ist eine initiale über 3 bis 4 Wochen verordnete Kombinationstherapie aus topischer Steroid- und CsA-Therapie eine sinnvolle Strategie.

\section{Andere nicht-Steroidale-Immunmodulatoren}

Der LFA-1 (,lymphocyte function associated antigen1")-Antagonist - wurde 2016 in den USA zugelassen. In der EU wurde der Zulassungsantrag im Jahr 2020 zurückgezogen. Es ist ein kompetitiver, niedermolekularer Integrin-Antagonist und blockiert die Bindung von LFA-1 an das interzelluläre Adhäsionsmolekül ICAM-1, welches auf Endothelzellen, Epithelzellen und antigenpräsentierenden Zellen exprimiert wird. Dies führt zu einer Hemmung der T-Zell-Migration in das Zielgewebe, reduziert weitere Zytokinfreisetzung und T-Zell-Rekrutierung [59-61]. Mehrere randomisiert kontrollierte Studien mit Lifitegrast (5\%) zeigten eine Linderung der subjektiven Symptome sowie der Oberflächenanfärbung bei Patienten mit Trockenem Auge [62]. Auf Grund des anderen Wirkmechanismus ist eine Kombination mit weiteren antiinflammatorischen Substanzen, z. B. CsA, denkbar und evtl. wirkungsverstärkend. Vorteilhaft ist, dass seine Wirkung zeitnäher, nämlich bereits nach 2 Wochen, einsetzt. Bei seiner Anwendung wurden Geschmacksstörungen berichtet.

Tacrolimus, ein Makrolid, das von Streptomyces tsukubaensis produziert wird, wurde 1984 in Japan bei der Suche nach einem neuen Immunsuppressivum entdeckt. Wie CsA blockiert es die Aktivität von T-Lymphozyten. Das immunsuppressive Potenzial ist jedoch höher ist als das von CsA. In einer prospektiven, doppelmaskierten klinischen Studie verbesserte die topische Applikation von 0,03\% Tacrolimus zweimal täglich, bei Patienten mit Sjögren-Syndrom den Oberflächenbefund. Tacrolimus könnte in Zukunft eine Alternative für Patienten mit Unverträglichkeit oder geringem Ansprechen auf topisches Ciclosporin sein [63].

\section{Omega-3- und -6-Fettsäuren}

In der modernen Ernährung hat sich die Aufnahme und damit das Gleichgewicht zwischen den essentiellen Omega-3- und Omega-6-Fettsäuren verschoben. In der westlichen Ernährung beträgt das Aufnahmeverhältnis typischerweise 15:1 (Omega-6 zu Omega3), während ein 4:1-Verhältnis im Allgemeinen als ideal betrachtet wird. Omega-3- und 6-Fettsäuren sind essentielle Fettsäuren, die vor allem in fetten Kaltwas- 
serfischen (Omega-3) und Pflanzensamen (Omega 3, Omega-6) vorkommen. Sie stehen als orale Nahrungsergänzungsmittel zur Verfügung.

Die Women's Health Study, an der über 32.000 Frauen teilnahmen, beschrieb einen Zusammenhang zwischen einer niedrigen ernährungsbedingten Aufnahme von Omega-3 und Trockenem Auge. Ein höheres Omega-6 zu Omega-3 Verhältnis war assoziiert mit einem höherem Risiko für ein Trockenes Auge (für 15:1 gegenüber <4:1, Odds Ratio: 2,51; $95 \%$ CI: 1,13; $5,58, P=0,01)$. Die Studie berichtete über eine $30 \%$ ige Risikoreduzierung mit jedem zusätzlichen Gramm an Omega-3 pro Tag. Es wurde außerdem eine höhere Omega-6 zu Omega-3-Ratio im Tränenfilm bei Patienten mit Trockenem Auge nachgewiesen [64].

Typischerweise werden Eicosapentaensäure (EPA) und Docosahexaensäure (DHA) in Dosen zwischen 1 und 2 g, abhängig vom Alter, der körperlichen Kondition und Aktivität empfohlen. Nach Empfehlungen des Dry Eye Workshops II von 2017 sollte die Nahrungsergänzung mit oralen Omega-3-Fettsäuren bereits in der ersten Behandlungsstufe erfolgen. Diese Empfehlung muss aufgrund der randomisiert kontrollierten DREAM-Studie an 535 Patienten, bei der kein Effekt dieser Therapie nachgewiesen werden konnte, relativiert werden [65].

\section{Biologika}

Biologika sind bio- oder gentechnologisch hergestellte Arzneistoffe und stellen einen rasch wachsenden Bereich der pharmazeutischen Industrie dar. In der Therapie von Augenoberflächenerkrankungen gibt es verschiedene innovative Ansätze.

Lubricin (Proteoglykan-4) ist ein schmierendes, muzinähnliches Glykoprotein, das erstmals in der Synovialflüssigkeit identifiziert wurde. In jüngerer Zeit wurde Lubricin auf der Augenoberfläche und in den Meibom-Drüsen entdeckt. Es ist ein hochwirksames reibungsminderndes Schmiermittel, funktioniert synergistisch mit HA und besitzt entzündungshemmende Eigenschaften. Derzeit sind keine Präparate auf Lubricin-Basis im Handel. Eine kürzlich veröffentlichte Studie verglich Augentropfen mit rekombinantem humanem Lubricin mit 0,18\%igen HA-Augentropfen und zeigte für Lubricin signifikante Besserung der okulären Befunde [66].

Rekombinanter menschlicher neurotropher Wachstumsfaktor (NGF) ist an der Regulation von Wachstum und Proliferation von Neuronen und Epithelzellen beteiligt und kommt natürlicherweise in den Tränen vor. Die Anwendung von NGF könnte durch Verbesserung der Hornhautsensitivität die Produktion des Tränenfilms anregen. Seit 2017 ist ein rekombinanter NGF (Cenergemin) als rezeptierbare, sehr kostenaufwändige Therapie der neurotrophen Keratopathie in Europa zugelassen. Ab 2020 wurde der Vertrieb des Präparats in Europa eingestellt.
Biologika bieten eine vielversprechende Zukunft in der Behandlung des Trockenen Auges. Weitere gut konzipierte Studien sind erforderlich, um ihre therapeutische Relevanz zu beurteilen.

\section{Hormontherapie}

Zahlreiche Studien haben versucht, die Wirksamkeit von Sexualhormonen bei der Behandlung des Trockenen Auges nachzuweisen. Aufgrund sehr unterschiedlicher Ergebnisse verschiedener randomisierter kontrollierter Studien, wird die Wirksamkeit einer solchen Therapie wissenschaftlich kontrovers diskutiert.

Gegenwärtig wird eine Hormonersatztherapie häufig bei postmenopausalen Frauen eingesetzt, um die mit dem Sexualhormonmangel verbundenen Symptome zu lindern. Golebiowski berichtet jedoch, dass eine transdermale Östrogentherapie die okulären Symptome bei postmenopausalen Frauen mit Trockenem Auge verschlimmern kann und eine transdermale Testosterontherapie keinen erkennbaren Einfluss auf die Symptome erkennen ließ [67]. Andere randomisiert kontrollierte Studien konnten eine Besserung der Symptome und Anzeichen des Trockenen Auges unter einer Phytoöstrogen-Supplementierung bei postmenopausalen Frauen nachweisen [68]. Somit sind die Rolle und die Vorteile einer Sexualhormontherapie bei der Behandlung des Trockenen Auges nach wie vor unklar und Gegenstand von Diskussionen.

\section{Androgene}

Androgene regulieren die Funktion der Tränen- und Meibom-Drüsen und ein Androgenmangel ist hauptverantwortlich für viele Prozesse, die zur Entwicklung einer Keratoconjunctivitis sicca führen.

Die Testosterongabe an weibliche Mäuse in einem Sjögren-Tiermodell führte zu einer dramatischen Suppression der Entzündung in der Tränendrüse und zu einem signifikanten Anstieg der Tränendrüsenfunktion [69]. Die lokale Applikation von 19-Nortestosteron bei Hunden mit Keratoconjunctivitis sicca bewirkte eine komplette Abheilung der entzündlich veränderten Tränendrüsen [70].

In einer kürzlich publizierten Metanalayse zeigten sechs Studien, dass Androgene, die über Salben oder Augentropfen verabreicht wurden, effektiv die Symptome des Trockenen Auges linderten und die Tränenstabilität über einen Zeitraum von 2 bis 4 Wochen erhöhten. Peri-menopausale Frauen und ältere (andropausale) Männer mit Androgenmangel sprachen am besten auf die Androgentherapie an [71].

\section{Chirurgische Therapie}

\section{Verschluss der ableitenden Tränenwege}

Der Verschluss der Tränenpünktchen kann probeweise für 48-72h mit Okklusiven aus Kollagen, für eine 
Tab. 2 Vergleich der verschiedenen Verfahren der Benetzungssubstitution durch Speicheldrüsen

\begin{tabular}{|c|c|c|c|}
\hline & Parotisgang-Verlagerung & GI. Submandibularis-Transposition & $\begin{array}{l}\text { Transplantation von } \\
\text { Mundschleimhaut mit } \\
\text { kleinen Speicheldrüsen }\end{array}$ \\
\hline Vaskularisation & Natürlich & Anastomosiert & Keine \\
\hline Innervation & Natürlich & Denerviert & Denerviert \\
\hline Globaler Sekrettyp & Serös & Seromuzinös & Muzinös \\
\hline $\begin{array}{l}\text { Spezifische } \\
\text { Sekretqualität }\end{array}$ & Natürlicher Parotisspeichel & $\begin{array}{l}\text { Speichelartig, aber mit Veränderungen in Richtung der natürlichen } \\
\text { Träne }\end{array}$ & Unbekannt \\
\hline Stimulation & Nahrungsaufnahme (reflektorisch) & Körperliche Aktivität, lokale Hyperthermie & Unbekannt \\
\hline Benetzungsmenge & $\begin{array}{l}\text { Dauerhafte Epiphora (nicht kontrol- } \\
\text { lierbar) }\end{array}$ & $\begin{array}{l}\text { In ca. einem Drittel: störende Epiphora (durch Teilresektion oder } \\
\text { Botulinumtoxin-Injektion kontrollierbar) }\end{array}$ & $\begin{array}{l}\text { Fraglich ausreichende Basal- } \\
\text { sekretion }\end{array}$ \\
\hline
\end{tabular}

längerfristige Wirkung aus Silikon oder permanent mit dem Kauter oder Laser erfolgen. Durch den verminderten Tränenabfluss verbleiben sowohl natürliche Tränen als auch Tränenersatzmittel länger auf der Augenoberfläche. Besonders geeignet sind Patienten mit niedrigen Schirmer-Test-Werten (0-5 mm ohne Anästhesie), die mit der häufigen Applikation von künstlichen Tränen nicht zurechtkommen, und eine Siccabedingte oder neurotrophe Keratopathie aufweisen. Auch die Symptomatik von Patienten mit okulärem vernarbendem Pemphigoid kann - neben der obligaten systemischen Therapie - durch die Implantation von Silikonstöpseln in die Tränenpünktchen erheblich verbessert werden. Allerdings sind gerade bei diesen Patienten die Tränenpünktchen häufig durch die Grunderkrankung bereits vernarbt. Zunächst wird in der Regel das untere Tränenpünktchen verschlossen. Bei Persistenz der Beschwerden kann zusätzlich das obere Tränenpünktchen okkludiert werden. Der Einsatz von Okklusiven bei Vorliegen einer Entzündung der Augenoberfläche ist umstritten, da theoretisch die Reduktion des Tränenabflusses die Verweildauer von pro-inflammatorischen Zytokinen auf der Augenoberfläche verlängert. Daher wird vielfach eine gleichzeitige antiinflammatorische Behandlung empfohlen. Allerdings hat eine rezente Studie zeigen können, dass eine 3-wöchige Punctum-Okklusion die Befunde eines moderat Trockenen Auges verbesserte und dabei Entzündungsmarker im Tränenfilm nicht erhöhte [72].

Neben Okklusiven für das Punctum lacrimale stehen auch intracanaliculäre Plugs aus Silikon, thermodynamischem Acrylpolymer oder Hydrogel zur Verfügung. Allerdings kann der Sitz, wie auch die Entfernung eines solchen intrakanalikulären Okklusivs, nicht kontrolliert werden.

Die häufigste „Komplikation“ ist der Verlust des Okklusivs. Selten kommt es zur Migration in den Tränennasengang mit Canaliculitis oder Entwicklung eines pyogenen Granuloms. In diesen Fällen ist die Entfernung des Fremdmaterials sowie eine antibiotische bzw. antientzündliche Therapie erforderlich. Nach Migration intracanaliculärer Plugs wurde auch die Entwicklung einer akuten Dakryozystitis beschrieben.

Patienten mit Kollagenosen und assoziierter Keratoconjunctivitis sicca benötigen manchmal einen per- manenten Verschluss der Tränenpünktchen. Die Indikation für diesen irreversiblen Eingriff muss allerdings sehr streng gestellt werden, um eine vom Patienten als sehr störend empfundene Epiphora zu vermeiden. Es empfiehlt sich daher, die Tränenwege zunächst immer mit reversiblen Techniken zu verschließen.

\section{Speicheldrüsen als Tränendrüsenersatz bei schwerster Keratoconjunctivitis sicca}

Bei absolutem Tränenmangel können die konservative Tränensubstitution oder chirurgische Verfahren (Verschluss der ableitenden Tränenwege, Tarsorrhaphie) unzureichend sein, um die Beschwerden des Patienten oder eine Progression der siccabedingten Epitheliopathie der Augenoberfläche zu kontrollieren. Als Folge des Trockenen Auges können rezidivierende, mikrobielle oder sterile Keratitiden in Kombination mit Wundheilungsstörungen zu Substanzverlust, Neovaskularisation und Eintrübung der Hornhaut bis zur Erblindung führen. Der Versuch einer funktionellen Rehabilitation mittels Keratoplastik ist meist frustran, da die Transplantatoberfläche aufgrund des Tränenmangels in kurzer Zeit die gleichen Probleme entwickelt. In diesen verzweifelten Fällen können körpereigene Speicheldrüsen zur Benetzung der okulären Oberfläche genutzt werden. Die drei zur Verfügung stehenden Optionen (Tab. 2) sind

- Transposition des Ausführungsganges der Ohrspeicheldrüse (Gl. parotis)

- Mikrovaskuläre Transplantation der Unterkieferspeicheldrüse (Gl. submandibularis)

- Freie Transplantation von Mundschleimhaut mit kleinen Speicheldrüsen

Die freie Transplantation der Unterzungendrüse (Gl. sublingualis) oder einer Tränendrüse selber konnte bislang nicht erfolgreich durchgeführt werden.

\section{Transposition des Parotisausführungsganges}

Filatov berichtete 1951 erstmalig über die Verlagerung des Stensonschen Ausführungsganges der Glandula parotis in den unteren Konjunktivalfornix. Andere Autoren bestätigten die Effektivität dieses Verfahrens. Da die Ohrspeicheldrüse bei diesem Verfahren in- 
nerviert bleibt und operativ nicht denerviert werden kann, ohne den Nervus facialis zu schädigen, kommt es ausnahmslos - besonders bei Nahrungsaufnahme - zu einer starken, reflektorischen Epiphora. Ein weiterer prinzipieller Nachteil dieses Verfahrens ist, dass das Sekret dieser Speicheldrüse rein serös ist und damit die funktionell wesentliche Muzinkomponente des vielschichtigen Tränenfilms fehlt. Das Verfahren hat sich klinisch nicht durchgesetzt.

\section{Freie Transposition der Glandula submandibularis mit mikrochirurgischer Revaskularisierung}

Murube-del-Castillo berichtete 1986 erstmalig über die freie Transplantation der autologen Gl. submandibularis in die Temporalregion zur Therapie des Trockenen Auges. Die Vitalität des Transplantates wird durch mikrovaskuläre Anastomosierung an die Arteria und Vena temporalis gesichert, das Sekret der Drüse durch den in den temporal oberen Fornix implantierten Drüsenausführungsgang zur Bindehaut geleitet. Präoperativ muss die Funktion der Drüse durch eine Technetium-Szintigraphie gesichert werden. Vorteilhaft bei diesem Verfahren sind die seromuzinöse Mischsekretion und die chirurgische Denervierung der Drüse, die eine gustatorischen Epiphora verhindert. Nachteilig ist die relativ aufwendige chirurgische Technik, die in $80 \%$ ein vitales Transplantat und hiervon wiederum in ca. $90 \%$ eine ausreichende bis überschießende Benetzung ( $5 \mathrm{~mm}$ oder mehr im Schirmer-Test) erzielen kann. Die Sekretion kann durch körperliche Aktivität und lokale Wärme über dem Transplantat stimuliert und durch lokale Injektion von Botulinumtoxin oder Teilresektion der Drüse kontrolliert werden. Die verbesserte Benetzung führt zu einer signifikanten Symptomreduktion und zum Rückgang der Epithelstippung [73, 74].

Die Zusammensetzung des natürlichen Submandibularis-Speichels unterscheidet sich jedoch deutlich von der natürlichen Träne. Vermutlich vorteilhaft sind sein Gehalt an Wachstumsfaktoren (z. B. EGF) und Abwehrstoffen (z. B. Lysozym, Immunglobulin A). Eine Toxizitätsstudie zeigte, dass der hohe Amylase-Gehalt des Speichels harmlos, seine Hypoosmolarität jedoch nachteilig ist [44]. Letztere ist vermutlich für die in Einzelfällen klinisch besonders bei dauerhafter Epiphora beobachtete Ausbildung eines diffusen Epithelödems verantwortlich. Auch die siccabedingte, typische squamöse Metaplasie des Bindehautepithels bildet sich trotz verbesserter Benetzung nicht zurück. Der relative operative Aufwand und die nicht tränengleiche Benetzungsqualität bedingen, dass dieses Verfahren verzweifelten Fällen absoluten Tränenmangels vorbehalten bleibt. Für diese Patienten bietet es jedoch die Möglichkeit zur deutlichen Symptomlinderung.

\section{Transplantation von Mundschleimhaut mit kleinen} Speicheldrüsen

Dieses Verfahren wurde ebenfalls von Murube-del-Castillo erstbeschrieben. Im Rahmen einer modifizierten Mundschleimhauttransplantation auf die bevorzugt tarsale Seite des oberen und/oder unteren Fornix wird gleichzeitig eine möglichst große Anzahl kleiner Speicheldrüsen mit übertragen. In einigen kleineren klinischen Kohorten wurde beobachtet, dass es zu einer Verbesserung des Schirmer-Testes, der Bindehautund Hornhautepitheliopathie und damit verbunden auch des Visus kommt. Schwere Komplikationen wurden nicht berichtet. Es können jedoch Lidfehlstellungen, insbesondere ein Ektropium induziert werden. In aller Regel ist jedoch die resultierende Sekretionsmenge relativ gering und die Qualität des Sekretes sehr muzinös. Dieses Verfahren kann von einem okuloplastisch versierten Chirurgen in schwersten Fällen eines quantitativen Tränenmangels durchgeführt werden. In aktuelleren retrospektiven Fallserien konnte eine langfristige Verbesserung des bestkorrigierten Visus und eine Reduktion der Anzeichen des Trockenen Auges [75], sowie eine $90 \%$ Überlebensrate des Speicheldrüsentransplantates mit intakter Basalsekretion nachgewiesen werden [76].

\section{Künstliche Tränenersatzmittelreservoire}

Wenn weniger invasiven Maßnahmen nicht ausreichen und als Alternative zu Speicheldrüsen kann bei absolutem Tränenmangel die Implantation eines künstlichen Flüssigkeitsreservoirs zur Aufnahme von Tränenersatzmitteln durchgeführt werden. Ähnlich einer Mikroinfusionspumpe bei der Insulinbehandlung von Diabetikern, sorgt ein kontinuierlicher Fluss aus dem Reservoir über einen Katheter für eine Oberflächenbenetzung. In einer prospektiven, nichtrandomisierten Studie mit 21 Probanden mit einer Schirmer-Wert von $1 \mathrm{~mm}$, wurde ein $60 \mathrm{ml}$-Reservoir subkutan in die vordere Bauchdecke implantiert und ein Silikonkatheter subkutan über Brust, Hals und Schläfe bis zum oberen Bindehautfornix geführt und sorgte durch eine kontinuierliche Oberflächenbenetzung für eine massiven Symptomlinderung. Eine Infektion des Reservoirs oder des Katheters ist denkbar und erfordert möglicherweise die Explantation $[77,78]$.

\section{Weitere therapeutische Möglichkeiten}

\section{Nasale Neurostimulation}

Es wurde ein intranasaler Neurostimulator entwickelt, welcher durch elektrische Stimulation der Nasenschleimhaut und Auslösen des nasolakrimalen Reflexes, zu einer gesteigerten Tränenproduktion führen soll. Seit 2017 ist ein Handgerät in den USA zugelassen (Truetear ${ }^{\mathrm{TM}}$ ), welches die Selbstverabreichung 
von winzigen elektrischen Strömen erlaubt. Durch Stimulation des Nervus ethmoidalis anterior konnte eine sofortige Anregung der Tränenproduktion gezeigt werden. Durch die nasale Stimulation konnte die Tränenfilmosmolarität gesenkt, die Ausschüttung von Tränenprotein erhöht und sowohl die Lipid- als auch die Muzinsekretion gesteigert werden [79, 80]. 2020 wurde die Produktion von Truetear ${ }^{\mathrm{TM}}$ vom Hersteller eingestellt.

\section{Schleimlösung}

Acetylcystein vermindert die Viskosität von Schleim. $5 \%$ ige Acetylcystein-Augentropfen können für eine kurze Zeit, z.B. bei Patienten mit Keratopathia filiformis, zur Beseitigung der Schleim-Epithelfäden nützlich und oberflächenglättend wirken. Sie müssen für den Patienten spezifisch hergestellt oder über die internationale Apotheke bestellt werden. Die Tränensubstitution bleibt unberührt.

\section{Schutzbrillen}

Schutzbrillen mit anatomisch angepasstem, am Kopf dicht ansitzendem Seitenschutz sind bei vielen Patienten hilfreich, um die normale Verdunstung der Tränen $\mathrm{zu}$ vermindern. Manchmal wird die Innenseite der Brille zur Verbesserung des Milieus befeuchtet. Wegen des kosmetisch unvorteilhaften Effektes werden solche Systeme leider von den Patienten oftmals abgelehnt. Es muss jedoch betont werden, dass ein entsprechender Seitenschutz auch an modische Brillen angebracht werden kann.

\section{Sklerallinsen}

Moderne Sklerallinsen haben in den letzten Jahren wieder steigendende Beliebtheit als medizinisches Hilfsmittel erfahren. Dies stellt ein Wiederaufleben des Sklerallinsenkonzepts nach der Erstbeschreibung in den 1990 Jahren dar und ist auf die Verfügbarkeit neuer Linsenmaterialien, verbesserte Topographiemessung und individuelle Linsenfertigung zurückzuführen. Mehrere Studien, in denen Sklerallinsen verwendet wurden, haben bei Patienten mit schwerem Trockenem Auge einen verbesserten Komfort, geringere Symptome und eine verbesserte Sehschärfe mit einem guten Sicherheitsprofil gezeigt. Trotz ihrer Wirksamkeit ist die Verwendung von Sklerallinsen nach wie vor Einzelfällen vorbehalten, was zum Teil auf die Verfügbarkeit, die Kosten und auf die Patientenakzeptanz zurückzuführen ist. Die Anwendung von Sklerallinsen erfordert eine genaue Patientenschulung, damit ein angemessener Umgang gewährleistet wird [81, 82].

\section{Nicht klassische Therapiemöglichkeiten des} Trockenen Auges

Es ist bekannt, dass Patienten mit Trockenem Auge nicht selten unter psychischer Fehlverarbeitung leiden. Die Erkrankung des Trockenen Auges ist häufig mit psychologischen Faktoren, wie Depression und Stress verbunden. Die Prävalenz von Schlaf-und Gemütsstörungen und bestimmte Charaktereigenschaften sind signifikant häufiger. Die Resilienz ist oft reduziert. Aus diesem Grunde sollte der Augenarzt bei Therapieversagern auch eine psychosomatische Begleittherapie in Erwägung ziehen [83].

Auch die Balneotherapie (Augenkurbehandlung) und die Akupunktur sollen für Betroffene positive Effekte erbringen können. Sowohl durch Laser- als auch durch Nadel-Akupunktur konnten in einer placebokontrollierten Studie bei 114 Patienten mit mäßiger bis schwerer Keratoconjunctivitis sicca subjektive Symptome, objektive Befunde und die Tropfhäufigkeit mit Tränenersatzmitteln signifikant reduziert werden $[84,85]$.

Seit Jahrhunderten haben einige Kulturen Honig in der Therapie verschiedener Erkrankungen verwendet. Manukahonig, ein traditionelles Neuseeländisches Naturheilmittel, zeigt in vitro antibakterielle Eigenschaften. Eine Augencreme auf Basis des antibakteriellen Wirkstoffes des Manukahonigs konnte die antimikrobielle Aktivität in präklinischen Tests bestätigen [86]. Weitere klinische Studien sind erforderlich, um die therapeutische Bedeutung dieser und anderer pflanzlicher oder natürlicher Formulierungen zu untersuchen.

\section{Behandlungsalgorithmus}

Behandlungsalgorithmen werden oft so konstruiert, dass sie einen Stufenbehandlungsplan nach Schweregrad angeben. Dies ist beim Trockenen Auge nur bedingt möglich, da es sich um ein komplexes und multifaktorielles Krankheitsbild handelt, welches nicht einem starren und evidenzbasierten Algorithmus folgt. Mit der Absicht Augenärzte zu unterstützen, wurde dennoch der Versuch unternommen einen Behandlungsalgorithmus $\mathrm{zu}$ entwickeln (vgl. Tab. 3 modifiziert nach DEWS II [1] und Leitlinie BVA und DOG).

Im Allgemeinen wird mit konventionellen, risikoarmen und allgemein verfügbaren Therapien begonnen. Nachdem eine Therapiestrategie eingeleitet wurde, ist eine sorgfältige Nachsorge erforderlich. Der übliche Zeitrahmen über den eine Therapieevaluation stattfinden sollte, hängt sowohl vom individuellen Ansprechen, als auch von der gewählten Therapieoption ab. Ein Literaturüberblick legt nahe, dass der Therapieerfolg einer Behandlung nach 1 bis 3 Monaten zu bewerten ist. Dies erscheint ein realistisches Zeitfenster und sollte dem Patienten auch so vermittelt werden. Für topisches Ciclosporin, aber auch systemische Tetra- 
Tab. 3 Behandlungsalgorithmus in der Therapie des Trockenen Auges (modifiziert nach DEWS II [28] und Leitlinie BVA und DOG 2019)

\section{Behandlungsalgorithmus}

Schritt I

Erläuterung von Ursachen, Umweltfaktoren, Verlauf und Therapie der Erkrankung

Korrektur von Lidfehlstellungen

Aufklärung über mögliche Ernährungsänderungen (einschließlich Supplementierung)

Identifizierung und ggf. Anpassung/Absetzten von systemischen und topischen Medikamenten mit bekannten Nebenwirkungen des Trockenen Auges

Verschiedene Arten von Tränenersatzmitteln (vgl. Tab. 1), bei Störung der Lipidphase des Tränenfilms lipidhaltiges Tränenersatzmittel

Lidkantenhygiene und Lidrandmassage

Falls nicht ausreichend, sind folgende Optionen zu prüfen:

Schritt II

Nicht konservierte Tränenersatzmittel zur Minimierung der konservierungsmittelbedingten Toxizität

Teebaumöl-Behandlung für Demodex (falls vorhanden)

Tränenwegokklusion durch alloplastisches Material (Okklusive aus verschiedenen Materialien im Punctum oder Canaliculus), Brille mit Seitenschutz

Übernachtbehandlungen (wie Salben- oder Uhrglasverband)

Ambulante thermisch-mechanische Behandlung (manuell oder geräteassistiert) bestehend aus Wärmeapplikation, Massage und Reinigung der Lidkanten

In Einzelfällen Eröffnung verschlossener Meibom-Drüsen (z. B. Sondierung) Insbesondere bei okulärer Rosacea: Lichtstimulation mittels hochenergetischer Lichtpulse (Intense pulsed light)

Topisches Antibiotikum oder Antibiotikum/Steroid-Kombination bei anteriorer Blepharitis (falls vorhanden)

Topisches Kortikosteroid (Behandlungsdauer begrenzen)

Topische Sekretagoga

Topische nicht-glukokortikoidale immunmodulierende Medikamente (wie Ciclosporin)

Topische LFA-1-Antagonisten (wie z. B. Lifitegrast)

Orale Makrolid- oder Tetracyclin-Antibiotika

Falls nicht ausreichend, sind folgende Optionen zu prüfen:

\section{Schritt III}

Orale Sekretagoga

Autologe/allogene Serum-Augentropfen

Verbandlinsen, Sklerallinsen

Falls nicht ausreichend, sind folgende Optionen zu prüfen:

\section{Schritt IV}

Topisches Kortikosteroid für längere Dauer

Amnionmembrantransplantation

Chirurgischer Punctumverschluss

Andere chirurgische Eingriffe (z. B. Tarsorrhaphie, Speicheldrüsentransplantation)

zyklinderivate sollte die therapeutische Wirksamkeit erst nach mehreren Monaten bewertet werden.

Funding Open Access funding enabled and organized by Projekt DEAL.

Interessenkonflikt G. Geerling: Consultant Speaker und Erhalt von Forschungsmitteln von Santen Pharmaceutical, Consultant Speaker für die Firma CHIESI, Consultant Speaker und Erhalt von Forschungsmitteln von Novartis, Consultant für MedlVentures, Consultant für die Firma Dompé. J.P. Korbmacher gibt an, dass kein Interessenkonflikt besteht.
Open Access Dieser Artikel wird unter der Creative Commons Namensnennung 4.0 International Lizenz veröffentlicht, welche die Nutzung, Vervielfältigung, Bearbeitung, Verbreitung und Wiedergabe in jeglichem Medium und Format erlaubt, sofern Sie den/die ursprünglichen Autor(en) und die Quelle ordnungsgemäß nennen, einen Link zur Creative Commons Lizenz beifügen und angeben, ob Änderungen vorgenommen wurden.

Die in diesem Artikel enthaltenen Bilder und sonstiges Drittmaterial unterliegen ebenfalls der genannten Creative Commons Lizenz, sofern sich aus der Abbildungslegende nichts anderes ergibt. Sofern das betreffende Material nicht unter der genannten Creative Commons Lizenz steht und die betreffende Handlung nicht nach gesetzlichen Vorschriften erlaubt ist, ist für die oben aufgeführten Weiterverwendungen des Materials die Einwilligung des jeweiligen Rechteinhabers einzuholen.

Weitere Details zur Lizenz entnehmen Sie bitte der Lizenzinformation auf http://creativecommons.org/licenses/by/4. $0 /$ deed.de.

\section{Literatur}

1. Jones L, Downie LE, Korb D, et al. TFOS DEWS II management and therapy report. Ocul Surf. 2017;15:575-628.

2. BruixA, AdanA, Casaroli-Marano RP.Efficacy of sodium carboxymethylcellulose in the treatment of dry eye syndrome. Arch Soc Esp Oftalmol.2006;81:85-92.

3. LeeJH, Ahn HS, Kim EK, Kim TI. Efficacy of sodium hyaluronate and carboxymethylcellulose in treating mild to moderate dry eye disease. Cornea. 2011;30:175-9.

4. Pucker AD, Ng SM, Nichols JJ. Over the counter (OTC) artificial tear drops for dry eye syndrome. Cochrane Database Syst Rev. 2016;2:CD9729.

5. Miyauchi S, Morita M, Kuramoto K, Horie K. Hyaluronan and chondroitin sulfate in rabbit tears. Curr Eye Res. 2009;15:131-5.

6. Oya T, Obata H, Miyata K, Tsuru T, Miyauchi S. Quantitative analyses of glycosaminoglycans in tear fluids in normal human eyes and eyes with corneal epithelial disorders. Nippon Ganka GakkaiZasshi. 1995;99:302-7.

7. Rah MJ. A review of hyaluronan and its ophthalmic applications. Optometry. 2011;82:38-43.

8. Hamano T, Horimoto K, Lee M, Komemushi S. Sodium hyaluronate eyedrops enhance tear film stability. Jpn J Ophthalmol. 1996;40:62-5.

9. Yamaguchi M, Kutsuna M, Maruo H, Hara Y, Uno T, Katao$\mathrm{kaH}$, et al. Sustained effects of sodium hyaluronate solution on tear film stability evaluated by tear stability analysis system. Nippon Ganka Gakkai Zasshi. 2011;115:134-41.

10. Johnson ME, Murphy PJ, Boulton M. Carbomer and sodium hyaluronate eyedrops for moderate dry eye treatment. Optom Vis Sci. 2008;85:750-7.

11. Camillieri G, Bucolo C, Rossi S, Drago F. Hyaluronan-induced stimulation of corneal wound healing is a pure pharmacological effect. J Ocul Pharmacol Ther. 2004;20:548-53.

12. Yokoi N, Komuro A, Nishida K, Kinoshita S. Effectiveness of hyaluronan on corneal epithelial barrierfunction in dryeye. BrJOphthalmol. 1997;81:533.

13. Simmons PA, Liu H, Carlisle-Wilcox C, Vehige JG. Efficacy and safety of two new formulations of artificial tears in subjects with dry eye disease: a 3-month, multicenter, active-controlled, randomized trial. Clin Ophthalmol. 2015;9:665-75. 
14. Otto S, Roth H-W. Wirksamkeit und Verträglichkeit eines Polyvidon-Präparates bei Behandlung von Benetzungsstörungen. Klin Monatsbl Augenheilkd. 1996;209:362-7.

15. Moon S-W, Hwang J-H, Chung S-H, Nam K-H. The impact of artificial tears containing hydroxypropyl guar on mucous layer. Cornea. 2010;29:1430-5.

16. Springs CL. Novel hydroxypropyl-guar gellable lubricant eyedrops for treatment of dry eye.AdvTher. 2010;27:681-90.

17. McDonald M, D'Aversa G, Perry HD, Wittpenn JR, Donnenfeld ED, Nelinson DS. Hydroxypropyl cellulose ophthalmic inserts (lacrisert) reduce the signs and symptoms of dry eye syndrome and improve patient quality of life. Trans Am Ophthalmol Soc. 2009;107:214-21.

18. Rolando M, Valente C. Establishing the tolerability and performance of tamarind seed polysaccharide (TSP) in treating dry eye syndrome: results of a clinical study. BMC Ophthalmol.2007;7:5.

19. Corrales RM, Luo L, Chang EY, Pflugfelder SC. Effects of osmoprotectants on hyperosmolar stress in cultured human corneal epithelial cells. Cornea. 2008;27:574-9.

20. Chen W, Zhang X, Li J, Wang Y, Chen Q, Hou C, et al. Efficacy of osmoprotectants on prevention and treatment of murine dry eye. Invest OphthalmolVis Sci. 2013;54:6287-97.

21. Troiano P, Monaco G. Effect of hypotonic $0.4 \%$ hyaluronic acid drops in dry eye patients: a cross-over study. Cornea. 2008;27:1126-30.

22. Baeyens V, Bron A, Baudouin C, Study GV. Efficacy of $0.18 \%$ hypotonic sodium hyaluronate ophthalmic solution in the treatment of signs and symptoms of dry eye disease. J Fr Ophtalmol.2012;35:412-9.

23. Chen W, Zhang X, Liu M, Zhang J, Ye Y, Lin Y, et al. Trehalose protects against ocular surface disorders in experimental murine dry eye through suppression of apoptosis. Exp Eye Res. 2009;89:311-8.

24. Sarkar S, Davies JE, Huang Z, TunnacliffeA, Rubinsztein DC. Trehalose, a novel mTOR-independent autophagy enhancer, accelerates the clearance of mutant huntingtin and alpha-synuclein. JBiolChem. 2007;282:5641-52.

25. Amrane M, Creuzot-Garcher C, Robert P-Y, Ismail D, Garrigue J-S, Pisella P-J, et al. Ocular tolerability and efficacy of a cationic emulsion in patients with mild to moderate dry eye disease-a randomised comparative study. J Fr Ophtalmol. 2014;37:589-98.

26. Geerling G, Tauber J, Baudouin C, Goto E, Matsumoto Y, O'Brien T, et al. The international workshop on Meibomian gland dysfunction: report of the subcommittee on management and treatment of Meibomian gland dysfunction. Invest OphthalmolVis Sci. 2011;52:2050-64.

27. Frings AGGHK. The influence of a cationic nanoemulsion or perfluorohexloctane on the lipid layer of the precorneal tear film and higher order aberrations. 2021.

28. Steven P, Augustin AJ, Geerling G, et al. Semifluorinated alkane eye drops for treatment of dry eye disease due to Meibomian gland disease. J Ocul Pharmacol Ther. 2017;33:678-85.

29. Finis D, Konig C, Hayajneh J, Borrelli M, Schrader S, Geerling G. Six-month effects of a thermodynamic treatment for MGD and implications of meibomian gland atrophy. Cornea. 2014;33:1265-70.

30. Finis D, Hayajneh J, Konig C, Borrelli M, Schrader S, Geerling G. Evaluation of an automated thermodynamic treatment (LipiFlow(R)) system for meibomian gland dysfunction: a prospective, randomized, observer-masked trial. Ocul Surf. 2014;12:146-54.

31. Vegunta S, Patel D, Shen JF. Combination therapy of intense pulsed light therapy and Meibomian gland expression (IPL/MGX) can improve dry eye symptoms and Meibomi- an gland function in patients with refractory dry eye: a retrospective analysis. Cornea. 2016;35:318-22.

32. Maskin SL. Intraductal meibomian gland probing relieves symptoms of obstructive meibomian gland dysfunction. Cornea. 2010;29:1145-52.

33. Fermon S, Zaga IH, Melloni DA. Intraductal meibomian gland probing for the treatment of blepharitis. Arch Soc Esp Oftalmol.2015;90:76-80.

34. Korb DR, Blackie CA. Debridement-scaling: a new procedure that increases Meibomian gland function and reduces dry eye symptoms. Cornea. 2013;32:1554-7.

35. AkpekEK, VittitowJ, Verhoeven RS, Brubaker K, Amar T, Powell KD, et al. Ocular surface distribution and pharmacokinetics of a novel ophthalmic $1 \%$ azithromycin formulation. JOcul Pharmacol Ther. 2009;25:433-40.

36. Liu Y, Kam WR, Ding J, Sullivan DA. Effect of azithromycin on lipid accumulation in immortalized human Meibomian gland epithelial cells. JAMAOphthalmol. 2014;132:226-8.

37. Liu Y, Kam WR, Ding J, Sullivan DA. Can tetracycline antibiotics duplicate theability of azithromycinto stimulate human meibomian gland epithelial cell differentiation? Cornea. 2015;34:342-6.

38. Gilbard JP. The scientific context and basis of the pharmacologic management of dry eyes. Ophthalmol Clin North Am. 2005;18:475-84.

39. Doughty MJ. On the prescribing of oral doxycycline or minocycline by UK optometrists as part of management of chronic Meibomian gland dysfunction (MGD). Cont Lens Anterior Eye. 2016;39:2-8.

40. KinoshitaS, AwamuraS, NakamichiN, Suzuki H, Oshiden K, Yokoi N, et al. A multicenter, open-label, 52-week study of $2 \%$ rebamipide (OPC-12759) ophthalmic suspension in patients with dry eye. Am J Ophthalmol. 2014;157:576-83.el.

41. Akpek EK, Lindsley KB, Adyanthaya RS, Swamy R, Baer AN, McDonnell PJ. Treatment of Sjogren's syndrome-associated dry eye an evidence-based review. Ophthalmology. 2011;118:1242-52.

42. Lau OC, Samarawickrama C, Skalicky SE. P2Y2 receptor agonists for the treatment of dry eye disease: a review. Clin Ophthalmol.2014;8:327-34.

43. Furrer P, Mayer JM, Gurny R. Ocular tolerance of preservatives and alternatives. Eur J Pharm Biopharm. 2002;53:263-80.

44. Geerling G, Daniels JT, Dart JK, Cree IA, Khaw PT. Toxicity of natural tear substitutes in a fully defined culture model of human corneal epithelial cells. Invest Ophthalmol Vis Sci. 2001;42:948-56.

45. Geerling G, Roth M. Pseudopemphigoid induced by topical glaucoma medications. Klin Monbl Augenheilkd. 2019;236:762-6.

46. Epstein SP, Chen D, Asbell PA. Evaluation of biomarkers of inflammation in response to benzalkonium chloride on corneal and conjunctival epithelial cells. J Ocul Pharmacol Ther. 2009;25:415-24.

47. Geerling G, Hartwig D. Autologe Serum-Augentropfen zur Therapie der Augenoberfläche. Ophthalmologe. 2002;99:949-59.

48. Fischer KR, Opitz A, Boeck M, Geerling G. Stability of serum eyedropsafterstorageof6months. Cornea. 2012;31:1313-8.

49. Watson SL, Secker GA, Daniels JT. The effect of therapeutic human serum drops on corneal stromal wound-healing activity. Curr Eye Res. 2008;33:641-52.

50. Harloff S, Hartwig D, Kasper K, Wedel T, Muller M, Geerling G. Epitheliotrophic capacity of serum eye drops from healthy donors versus serum from immunosuppressed patients with rheumatoid arthritis. Klin Monbl Augenheilkd. 2008;225:200-6. 
51. Akyol-Salman I. Effects of autologous serum eye drops on corneal wound healing after superficial keratectomy in rabbits. Cornea. 2006;25:1178-81.

52. Spaniol K, Koerschgen L, Sander O, Koegler G, Geerling G. Comparison of application systems for autologous serum eye drops. Curr Eye Res. 2014;39:571-9.

53. Marsh P. Topical nonpreserved methylprednisolone therapy for keratoconjunctivitis sicca in Sjögren syndrome. Ophthalmology. 1999;106:811-6.

54. Periman LM, MahFS, Karpecki PM. A review of the mechanism of action of cyclosporine A: the role of cyclosporine A in dry eye disease and recent formulation developments. Clin Ophthalmol.2020;14:4187-200.

55. Yoshida A, Fujihara T, Nakata K. Cyclosporin Aincreases tear fluid secretion via release of sensory neurotransmitters and muscarinic pathway in mice. Exp Eye Res. 1999;68:541-6.

56. Straub M, Bron AM, Muselier-Mathieu A, Creuzot-Garcher C. Long-term outcome after topical ciclosporin in severe dry eye disease with a 10-year follow-up. Br J Ophthalmol.2016;100:1547-50.

57. Pleyer U, Geerling G, Schrader S, Jacobi C, Kimmich F, Messmer E. If artificial tears aren't enough. The importance of inflammatory processes in dry eye disease. Practical aspects of an anti-inflammatory therapy of dry eye disease. Klin Monbl Augenheilkd. 2020;237:655-68.

58. Sheppard JD, Scoper SV, Samudre S. Topical loteprednol pretreatment reduces cyclosporine stinging in chronic dry eye disease. J Ocul Pharmacol Ther. 2011;27:23-7.

59. Zhong M, Gadek TR, Bui M, et al. Discovery and development of potent LFA-1/ICAM-1 antagonist SAR 1118 as an ophthalmic solution for treating dry eye. ACS Med Chem Lett. 2012;3:203-6.

60. Sun Y, Zhang R, Gadek TR, O'Neill CA, Pearlman E. Corneal inflammation is inhibited by the LFA-1 antagonist, lifitegrast (SAR 1118). J Ocul Pharmacol Ther. 2013;29:395-402.

61. Perez VL, Pflugfelder SC, Zhang S, Shojaei A, Haque R. Lifitegrast, a novel integrin antagonist for treatment of dry eye disease. Ocul Surf. 2016;14:207-15.

62. Donnenfeld ED, Karpecki PM, Majmudar PA, Nichols KK, Raychaudhuri A, Roy M, et al. Safety of Lifitegrast ophthalmic solution $5.0 \%$ in patients with dry eye disease: a 1 -year, multicenter, randomized, placebo-controlled study. Cornea. 2016;35:741-8.

63. Moscovici BK, Holzchuh R, Sakassegawa-Naves FE, Hoshino-Ruiz DR, Albers MB, Santo RM, et al. Treatment of Sjogren's syndrome dry eye using $0.03 \%$ tacrolimus eye drop: prospective double-blind randomized study. Cont Lens Anterior Eye. 2015;38:373-8.

64. Miljanovic B, Trivedi KA, Dana MR, Gilbard JP, Buring JE, Schaumberg DA. Relation between dietary n-3 and n-6 fatty acids and clinically diagnosed dry eye syndrome in women. AmJ Clin Nutr. 2005;82:887-93.

65. Eye AD, Research GMS, Asbell PA, Maguire MG, Pistilli M, Ying GS, et al. n-3 fatty acid supplementation for the treatment of dry eye disease. NEnglJ Med. 2018;378:1681-90.

66. Lambiase A, Sullivan BD, Schmidt TA, Sullivan DA, Jay GD, Truitt ER, et al. A two-week, randomized, double-masked study to evaluate safety and efficacy of lubricin $(150 \mu \mathrm{g} / \mathrm{mL})$ eye drops versus sodium hyaluronate (HA) $0.18 \%$ eye drops (Vismed ${ }^{\circledR}$ ) in patients with moderate dry eye disease. Ocul Surf. 2017;15:77-87.

67. Golebiowski B, Badarudin N, Eden J, Gerrand L, Robinson J, Liu J, et al. The effects of transdermal testosterone and oestrogen therapy on dry eye in postmenopausal women: a randomised, placebo-controlled, pilot study. Br J Ophthalmol.2017;101:926-32.

68. Scuderi G, Contestabile MT, Gagliano C, Iacovello D, Scuderi L, Avitabile T. Effects of phytoestrogen supplementation in postmenopausal women with dry eye syndrome: a randomized clinical trial. Can J Ophthalmol. 2012;47:489-92.

69. Sullivan DA, Edwards JA. Androgen stimulation of lacrimal gland function in mouse models of Sjogren's syndrome. JSteroid Biochem Mol Biol. 1997;60:237-45.

70. Gao J, Gelber-Schwalb TA, Addeo JV, Stern ME. Apoptosis in the lacrimal gland and conjunctiva of dry eye dogs. Adv Exp MedBiol. 1998;438:453-60.

71. Wang L, Deng Y. The applications of androgen in the treatment of dry eye disease: a systematic review of clinical studies. Endocr J.2020;67:893-902.

72. Tong L, Beuerman R, Simonyi S, Hollander DA, Stern ME. Effects of punctal occlusion on clinical signs and symptoms and on tear cytokine levels in patients with dry eye. Ocul Surf. 2016;14:233-41.

73. Geerling G, Sieg P, Bastian GO, Laqua H. Transplantation of the autologous submandibular gland for most severe cases of keratoconjunctivitis sicca. Ophthalmology. 1998;105:327-35.

74. Borrelli M, Schroder C, Dart JK, et al. Long-term follow-up after submandibular gland transplantation in severe dry eyes secondary to cicatrizing conjunctivitis. Am J Ophthalmol.2010;150:894-904.

75. Vazirani J, Bhalekar S, Amescua G, Singh S, Basu S. Minor salivary gland transplantation for severe dry eye disease due to cicatrising conjunctivitis: multicentre long-term outcomes of a modified technique. Br J Ophthalmol. 2020; https://doi.org/10.1136/bjophthalmol-2020-316611.

76. Geerling G, Raus P, Murube J. Minor salivary gland transplantation. Dev Ophthalmol.2008;41:243-54.

77. Murube J, Murube E, ChenZhuo L, Rivas L. Subcutaneous abdominal artificial tears pump-reservoir for severe dry eye. Orbit. 2003;22:29-40.

78. Murube GGJ. Mechanical pump dacryoreservoirs. Dev Ophthalmol.2008;41:269-82.

79. Brinton M, Kossler AL, Patel ZM, Loudin J, Franke M, Ta CN, et al. Enhanced tearing by electrical stimulation of the anterior ethmoid nerve. Invest Ophthalmol Vis Sci. 2017;58:2341-8.

80. Gumus K, Schuetzle KL, Pflugfelder SC. Randomized controlled crossover trial comparing the impact of sham or Intranasal tear neurostimulation on conjunctival goblet cell degranulation. Am J Ophthalmol. 2017;177:159-68.

81. Hanisch KT, Neppert B, Geerling G. Gas permeable scleral lenses as a conservative treatment option for extreme corneal ectasias and severe dry eye. Ophthalmologe. 2005;102:387-92.

82. Tappin MJ, Pullum KW, Buckley RJ. Scleral contact lenses for overnight wear in the management of ocular surface disorders. Eye (Lond). 2001;15:168-72.

83. Kaiser T, Janssen B, Schrader S, Geerling G. Depressive symptoms, resilience, and personality traits in dry eye disease. GraefesArchClinExpOphthalmol.2019;257:591-9.

84. Rieger G, Winkler R, Stoiser E. Zur Wirkungsdauer balneotherapeutischer Maßnahmen bei Patienten mit Beschwerden des „trockenen Auges“. Spektrum Augenheilkd. 1997;11:255-7.

85. Nepp J, Wedrich A, Akramian J, Derbolav A, Mudrich C, Ries E, Schauersberger J. Lacrimal gland, tear film, and dry eye syndromes 2 , basic science and clinical relevance. Advances in experimental medicine and biology. 1998. S. 1011-6.

86. Craig JP, Rupenthal ID, Seyfoddin A, Cheung IMY, Uy B, Wang MTM, et al. Preclinical development of MGO Manuka Honey microemulsion for blepharitis management. BMJ Open Ophthalmol.2017;1:e65. 


\section{themenschwerpunkt}

Hinweis des Verlags Erstpublikation in: Messmer, Elisabeth, Therapie des Trockenen Auges, 2. Auflage 2021, UNI-MED Verlag Bremen.

Der Verlag bleibt in Hinblick auf geografische Zuordnungen und Gebietsbezeichnungen in veröffentlichten Karten und Institutsadressen neutral. 